\title{
LA REPRÉSENTATION DE LA COURONNE PORTUGAISE À AVIGNON ET SES AGENTS (1305-1377)
}

\author{
THE REPRESENTATION OF PORTUGUESE CROWN \\ AT AVIGNON AND ITS AGENTS (1305-1377)
}

\author{
MÁRIO FARELO ${ }^{1}$ \\ Instituto de Estudos Medievais \\ Universidade Nova de Lisboa \\ Centro de Estudos de História Religiosa \\ Universidade Católica portuguesa
}

\begin{abstract}
Résumé: La poursuite des affaires de la Couronne portugaise à la curie d'Avignon a amené la constitution de deux types de représentation. L'une, de caractère formelle, constituée par des ambassadeurs choisies ad casu au profil varié. L'autre, agencée autour des clercs séjournant de forme permanente à la curie. Les uns comme les autres intervinrent dans la concrétisation des demandes gracieuses ou fiscales au nom du roi ou de bénéfices pour eux et leurs clientèles.
\end{abstract}

Mots-clés: Ambassades; Royauté; Portugais à Avignon; Curie; Décimes ecclésiastiques.

\begin{abstract}
The continuation of the businesses of the Portuguese Crown to the curia of Avignon brought the constitution of two types of representation. One, of formal character, consisted of ambassadors chosen ad casu with different social backgrounds and other constituted by clerks living continuously at Avignon. The ones like the others intervened in the concretization of the gracious or tax requests in the name of the king or of benefit for them and their clients.
\end{abstract}

Keywords: Embassies; Royalty; Portuguese at Avignon; Curia; Ecclesiastical tithes.

\section{SOMMAIRE}

1. Les sources.- 2. Les représentations de la Couronne: les ambassades formelles.3. Les représentations de la Couronne: les représentants sur place.

Le Portugal du XIV ${ }^{\mathrm{e}}$ siècle est un royaume qui s'insère dans l'espace de la Chrétienté occidentale par l'importance de sa liminalité géographique. Son emplacement favorable du point de vue géostratégique favorise les

\footnotetext{
${ }^{1}$ Boursier dans le cadre d'un projet de post doctorat subventionné par la Fondation pour la Science et la Technologie portugaise (programme POCI2010/EFS) intitulé Le royaume du Portugal et l'interventionnisme de la Papauté d'Avignon (1305-13.77). Ce projet, dans lequel s'inscrit cet article, a été accueilli depuis mai 2009 par le Centre d'Etudes d'Histoire Religieuse de l'Université Catholique portugaise (CEHR) sous la direction d'Hermínia Vilar, par l'Ițstitut d'Etudes Médiévales de l'Université Nouvelle de Lisbonne (IEM) dans l'unité d'investigation Poderes Medievais: Agentes e Espaços sous la responsabilite de Luís Filipe Oliveira et par le Laboratoire de Médiévistique Occidentale de Paris (LAMOP) dans l'axe Eglise, corps social sous la responsabilité d'Hélène Millet.
} 
contacts économiques entre le nord atlantique et la méditerranée où il jouit d'une position charnière en termes de la circulation de marchandises et de capitaux gérés par un commerce international qui gagne un incrément notoire avec la conquête de l'Étroit et qui rend appétissant le marché ibérique une fois établie la crise généralisée des marchés septentrionaux ${ }^{2}$. Dépourvu du poids politique, humain et économique de ses voisins et incapable d'intervenir de forme soutenue sur la scène internationale, sa géographie le place dans la zone méridional de la péninsule, laquelle se caractérise comme une zone de frontière à bras avec les investies systémiques des musulmans marocains e magrébins. Cette possibilité de croisade demeure l'une des plus importantes dimensions des relations entre le Portugal et les autres entités politiques extra pyrénéens, notamment avec la Papauté.

En effet, le thème de la croisade demeure au XIV ${ }^{\mathrm{e}}$ siècle un des piliers des relations entre Avignon et le Portugal, ne serait-ce en tant qu'argument pour terminer les conflits ponctuellement survenus entre les souverainetés ibériques. En termes concrets, les périodes d'intense activité curiale procroisades retrouvent l'écho à la péninsule, soit par la volonté pontificale à faire enliser le Portugal dans les plans de croisade international à la destination de la Terre Sainte, soit par la volonté de la couronne lusitanienne à défendre l'idée de la Croisade «régionale», à laquelle Avignon adhère avec reluctance par la concession ponctuelle de décimes ecclésiastiques ${ }^{3}$.

${ }^{2}$ A.H. de Oliveira Marques, Portugal na Crise dos séculos XIV e XV, Lisboa, 1987, p. 151154. Pour l'action portugaise pendant le demi-siècle de confrontation en termes de la domination de l'étroit de Gibraltar et la conséquente analyse des faits, voir les indications contenues dans Luís Adão da FonsECA, Portugal na Península Ibérica. Horizontes marítimos, articulação política e relações diplomáticas (séc. XII-XVI), in Las Españas Medievales (J. VALDEÓN BARUQUE, ed.) Valladolid, p. 83-93; Manuel GARCIA FERNÁNDEZ, Las relaciones internacionales de Alfonso IV de Portugal y Alfonso XI de Castilla en Andalucía (L a participación portuguesa en la gran batalla del Estrecho, 1325-1350, in Actas das II jornadas luso-espanholas de História Medieval, vol. I, Porto 1987, $\mathrm{p}$ 201-216; id. La política internacional de Portugal y Castilla en el umbral de la Baja Edad Media. Nuevas reflexiones sobre los viejos sistemas de alianzas dinásticas peninsulares (1279-1357), «Revista de Ciencias Historicas», XIV (1999), p. 61-80; id., Navegacion y comercio português por el Mediterráneo occidental en tiempos de Alfonso IV (Apuntes sobre el secuestro de naves lisboetas por corsários catalanes entre 1333-1334), in La Península Ibérica entre el Mediterráneo y el Atlántico. Siglos XIII-XV (M. GONZÁLEZ JIMÉNEZ et I. MONTES ROMEROCAMACHO, eds.), Sevilla-Cadiz, 2006, p. 395-407 et Manuel ROJAS, De la estrategia en la "Batalla del Estrecho" durante la primera mitad del siglo XIV [C. 1292-1350], in El Siglo XIV. El alba de una nueva era, Soria, 2001, p. 223-269.

${ }^{3}$ Avec une très grande expression pendant la deuxième moitié du XIV ${ }^{\mathrm{e}}$ siècle, précisément entre 1320 et 1377. La concession de ces décimes avait l'intention claire, à son début, de faire diminuer les structures de support des musulmans. Ainsi, la concession de la décime triennale de 1320 octroyée à Denis se destinait à renforcer la flotte portugaise afin qu'elle puisse éradiquer de forme efficace la piraterie musulmane sur les côtes de l'Algarve et de l'Alentejo. De plus, il est possible de constater à partir de 1341 un intérêt dans ce que nous pouvons dénommer de guerre offensive. Si, à cette date, le pape est d'accord avec la possibilité d'une attaque portugaise aux musulmans par voie maritime ou terrestre, il énonce formellement dans la concession de 1376 que, à la suite de la conquête, il faudrait construire des cathédrales et que les décimes et prémisses devraient être payées à partir dẹs biens alors pris. Les concessions octroyées pendant cette période ont été les suivantes: une décime triennal en 1320 (Descobrimentos portugueses. Documentos para a sua história (J. MARQUES, ed.), vol. I, Lisboa, 1944, p. 133-139); une décime biennale en 1341 pour la guerre défensive et offensive contre les Maures de Granada (Monumenta Henricina (A. DIAS, ed.), vol. I, Lisboa, 1960, p. 178-194, 199-201); une autre décime biennale en 1345 (Descobrimentos Portugueses, vol. I, p. 83 et Monumenta Henricina, vol. I, p. 217-221); une décime quadriennale en 1355 pour reprendre les châteaux que les chrétiens avạient perdu en Algarve (Descobrimentos Portugueses, vol. I, p. 100-103 et Monumenta Henricina, vol. I, p. 239-243); une demi-décime biennale décidée en 1376 (Descobrimentos Portugueses, vol. I, p. 150-154 (datée de 1376) et Monumenta Henricina, vol. I, p. 247-250 (datée de 1375) et une autre 
Cette reconnaissance d'un rôle important dans le blocage de la pénétration musulmane dans la Chrétienté occidentale reste une piètre récompense pour le peu de poids politique et économique que ce royaume représente pour la Papauté. Dès lors, par le fait que la royauté portugais n'a pas pu compter sur un compatriote au collège des cardinaux. Même si ce critère n'est pas le plus sûr pour attester cette faiblesse ${ }^{4}$, il n'en demeure pas moins que la démarche diplomatique des rois portugais a dut pâtir de cette absence dans l'organisation d'un lobby efficace à la Curie. De plus, sur le point de vue financier, il ne faut pas oublier que la collectorie portugaise semble avoir été de maigres revenus sans les sommes provenant des décimes et des dépouilles des prélats (ius spolii) $)^{5}$. Ce manque de poids politique est exploité par la Papauté et, en ce sens, un épisode comme la question des îles Canaries dans les années 1340 montre toute la faiblesse de la diplomatie d'Alphonse IV (1325-1357) ${ }^{6}$.

demi-décime biennale l'année suivante (Descobrimentos Portugueses, vol. I, p. 162-165 et Monumenta Henricina, vol. I, p. 252-257). Les demandes non concédées peuvent être recensées à partir de notre tableau I.

Il est curieux que le roi puisse mettre en scène une guerre fictive contre l'Infidèle pour essayer de retenir les décimes que le pape lui avait concédées, selon l'opinion d'un collecteur apostolique au Portugal en 1328. Malheureusement, nous n'avons pas pu confirmer ces affirmations, puisqu'elles découlent du sommaire d'un document vu par Garampi dont nous avons depuis perdu la trace. Déjà au $X^{\mathrm{e}}$ siècle, l'excellent connaisseur des lettres apostoliques qu'était Guillaume Mollat n'est pas arrivé à repérer l'original (Lettres communes du pape Jean XXII (1316-1334). Lettres communes analy sées d'après les Registres dits d'Avignon et du Vatican, (G. Mollat, ed.), 1904-1947, n ${ }^{\circ} 42497$ [dorénavant LCJXXII] commenté dans Norman Housley, The Avignon Papacy and the Crusades 1305-1378, Oxford, 1986, p. 104. Ces deux thèmes ont été développés dans une communication intitulé A Cruzada, a Coróa e a fiscalidade no século XIV présentée par Luís Filipe Oliveira et Mário Farelo aux VI Jornadas LusoEspanholas de Estudos Medievais déroulées entre le 6 et le 8 novembre de 2008 . Après des retards qui ne peuvvent être imputables qu'aux auteurs, il n'a pas été posssible de la publier dans les actes de ces journées, entretemps parues. Elle sera l'objet de publication prochainement. Entretemps, des indications sur ces matières peuvent être recueillies dans les textes de José ANTUNES, Um apelo à invasão da Africa em 1344. Do Salado a Ceuta, «Biblos - Revista da Faculdade de Letras da Universidade de Coimbra», LXXVIII (2002), p. 135-148 et Iria GoNÇALVES, Pedidos e Empréstimos Públicos em Portugal Durante a Idadé Média, Lisboa, 1964.

${ }^{4}$ Puisque d'aụtres nations plus «puissances» pendant cette période ont passé de nombreux années sans réussir à faire élire l'un des siens au Sacré-collège. L'importance de telles présences peut être reconnue par les intenses négociations en ce sens entamées par les couronnes d'Aragon et de l'Angleterre (Rafael OLIVAR BERTRAND, Alfonso IV el Benigno quiere un cardenal de sus reinos, "Estudios de Edad Media de la Corona de Aragón», 4 (1951), p. 156-176; Karsten PLÖGER, England and the Avignon Popes. The Practice of Diplomacy in Late Medieval Europe, Oxford, 2005, p. 28-29). Sous-jacente à cette situation se trouve la prédominance dans le Sacrécollège des cardinaux des compatriotes des papes avignonnais, notamment issus du Quercy et du Limousin, dans la France actuelle.

${ }^{5} \mathrm{C}$ 'est en tout cas ce qui affirme le collecteur Bertrand du Mazel. Jean GLÉSISSON, Un agent de la Chambre Apostolique au XIV siècle. Les missions de Bertrand du Mazel (1364-1378), "Mélanges d'archéologie et d'histoire de l'Ecole Française de Rome», 59 (1947), p. 101 [en ligne: http://www.persee.fr/wêb/revues/home/prescript/article/mefr 0223-4874'1947 num 59 1 7338].

${ }^{6}$ La concession de cette île en 1344 à Louis de la Cerda retarde l'exploitation d'une hypothétique aire d'expansion atlantique débutée probablement dès la décennie antérieure. Grégoire XI agira avec plus de bienveillance envers Ferdinand ${ }^{\text {er }}$ trois décennies plus tard, lorsqu'il sera question de passer à la guerre offensive en Afrique du nord. Sur la «question» des îles Canaries, voir Covadonga VALDALISO CASANOVA, Los pilares medievales de la expansión ultramarina: los reyes de las Islas Canarias en le siglo XIV, in La Península Ibérica entre el Mediterráneo y el Atlántico. Siglos XIII-XV (M. GoNZÁLEZ JIMÉNEZ et I. MONTES ROMEROCAMACHO, eds., Sevilla-Cadiz, 2006, p. 703-709 et Isabel L. Morgado de S. e SILVA, Perspectiva glob̆al das viagens dos portugueses às Canárias no âmbito dos descobrimentos e expansão portuguesa. Uma questâo adiada até Alcaçovas-Toledo (1479-80) «Revista da Faculdade de Letras [da Universidade do Porto] - História», III série 7 (2006), p. 95-98. [édition en ligne: ler.letras.up.pt/uploads/ficheiros/3406.pdf], ainsi que la bibliographie recensée au long 
La projection curiale réduite du royaume lusitanien n'empêchait pas les relations entre les deux pouvoirs. Celles-ci sont bien sûr de nature différente de celles entre les états souverains, puisqu'elles relèvent d'une verticalité plutôt que d'une relation horizontale. Comme souligné récemment, le roi souverain ne peut «acheter la loyauté du pape, extraire des serments d'allégeance ou d'hommage, les défier formellement et lui faire la guerre et - pour des raisons encore plus évidentes- ne peut pas lui marier sa fille» ${ }^{7}$. Cette inégalité est d'ailleurs reconnue pour tous les agents intervenants. D'une part, le pouvoir apostolique agit dans sa qualité de pouvoir souverain qui s'affirme comme régulateur des affaires ecclésiastiques et bénéficiales au niveau de la Chrétienté. Avec plus ou moins de succès selon les cas, il se pose en médiateur en tant que pouvoir suprême des conflits survenus entre les puissances chrétiennes, dont il s'efforce de légitimer l'action guerrière lorsqu'il s'agit de la croisade contre l'Infidèle. En ce qui concerne le Portugal, la Papauté traite le royaume au même titre que les autres états souverains, puisque les rois lusitaniens reçoivent, entre autres, les annonces des nouveaux pontificats et les invitations pour les réunions conciliaires œcuméniques ${ }^{8}$. Son espace restreint, formé de deux entités distinctes, le Portugal et l'Algarve ${ }^{9}$, est assimilé par la Chambre apostolique à une même entité du point de vue fiscal. La collectorie portugaise s'étend ainsi sur tout l'espace politique, à une époque où les frontières ecclésiastiques n'étaient pas encore celles de la géographie politique. Toutefois, cela ne veut pas dire que la papauté ne reconnaît pas l'aire régionale ibérique. Celle-ci refait surface chaque fois qu'il se pose des questions globales, à l'instar de la destinée des biens péninsulaires de l'ordre du Temple dissoute par Clément V lors du concile de Vienne ${ }^{10}$ ou la croisade planifiée par Benoît XII durant la première partie de la décennie 1330 et qui mérita du roi Alphonse IV une réponse tout à fait «régionale» ${ }^{11}$.

En réalité, c'est à l'échelle régionale qui se déroulait l'essentielle de l'actuation politico-diplomatique portugaise. S'il est vrai que le royaume

de ces travaux.

${ }^{7}$ K. PLÖGER, England and the Avignon Popes, p. 5.

${ }^{8}$ Comme celles pour le concile de Vienne, datées respectivement du 12 août 1308 et du 4 d'avril 1310. Regestvm Clementis papae Vex vaticanis archetypis sanctissimi domini nostri Leonis XIII pontificis maximi ivssv et mvnificenta, nvnc primvm editvm cvra et stvdio monachorvm ordinis s. Benedicti, Romae, 1885-1892, no 3626, 6294.

${ }^{9}$ André Oliveira LeITÃo, Do Garb al-Ândalus ao «segundo reino» da «Coroa de Portugal»: território política e identidade, "Clio. Revista do Centro de história da Universidade de Lisboa», 16-17 (2007), p. 69-104.

${ }^{10}$ Les royaumes de Castille, Aragon, Portugal et Maiorca se sont fait exempter du transfert de ces biens à l'ordre des Hospitaliers. Monumenta Portugaliae Vaticana Antonio Domingues de Sousa COSTA, ed), Roma-Braga, 1968, vol. I, p. XLI. [dorénavant MPV].

${ }^{11}$ Le roi soutien dans une lettre à son genre Afonso XI de Castille la poursuite de la croisade en sol ibérique au détriment d'un passage outre-mer, argumentant avec la distance et la nécessite de transmettre à la descendance un territoire libre de toute domination de l'Infidèle (Ruy de PINA, Chronica de Elrey Dom Afonso o Quarto, Lisboa, 1936, chap. XXV, p. 71-74; Luis Vicente DÍAZ MARTín, El papel del pontificado en las relaciones franco-castellanas, en la época de Juan II de Francia, in Les communications dans la péninsule ibérique au Moyen-Age. Actes du colloque tenu à Pau les 28 et 29 mars 1980 (P. TUCOO-CHALA, dir), Paris, 1981, p. 57. Sur ce projet de croisade, voir Christopher J. TYERMAN, Philip VI and the Recovery of the Holy Land, "English Historical Review», 100 (1985), p. 25-52. 
développe alors des relations de ce type avec les pays extra pyrénéens ${ }^{12}$, il faut admettre que le gros de l'activité politique développée par le Portugal au XIV ${ }^{\mathrm{e}}$ siècle concerne avant tout ses voisins ibériques, notamment la Castille et l'Aragon. C'est avec la première qu'il est intermittemment en guerre ${ }^{13}$, de la même façon que c'est vers les aires castillanes et aragonaises que la Couronne lusitanienne semble diriger l'effort de leur activité de la «haute-politique» marquée pour les ambassades et la célébration des traités autour de la recherche de reines étrangères et le placement des princesses lusitaniennes.

Le Portugal agit en état souverain, reconnu par les autres royaumes «européens» et par la Papauté, doté d'une souveraineté, d'une légitimité et d'une capacité financière pour disposer des moyens formels de contact à l'échelle de la Chrétienté. Comme tous ces homologues à l'époque, la royauté portugaise a senti aussi la nécessité d'établir des canaux de communication avec le pouvoir apostolique siégé à Avignon. Il faut avouer que l'emplacement lointain de ce dernier vis-à-vis l'Ibérie a toujours déconseillé des rendez-vous de viva voce entre le roi et le pape. Il a fallut donc s'en tenir à une représentation dont il faut chercher les indices, aussi bien dans la documentation portugaise que dans celle aujourd'hui conservée aux archives vaticanes.

\section{LES SOURCES}

L'étude des relations diplomatiques portugaises avec la papauté d'Avignon souffre de forme notoire des limitations historiographiques ${ }^{14}$ et de

\footnotetext{
${ }^{12}$ Pour cette période, ce sont les relations politico-diplomatiques avec l'Angleterre et la France qui sont les plus référées par une historiographie qui a bien vieillie, mais qui nécessite encore d'une investigation fondamentale pour consolider les conjonctures et perspectives d'analyse, lesquelles demeurent très liés à l'activité commerciale et à l'établissement de l'inventaire des traités célébrés entre les royaumes. Voir prochainement le volume sur l'historiographie médiévale portugaise en procès d'élaboration au sein de l'Instituto de Estudos Medievais avec la collaboration de plusieurs médiévistes portugais.

${ }^{13} \mathrm{Les}$ guerres luso-castillanes qui eurent lieu pendant la période avignonnaise furent celles en 1336-1339, $1369-1371$ et 1372-1373. Voir Miguel Gomes MARTINS, A guerra esquiva. O conflito luso-castelhano de 1336-1338, «Promontoria. Revista do Departamento de Historia, Arqueologia e Património da Universidade do Algarve» Année 3/3 (2005), p. 19-80 et Armando MARTINS, Guerras Fernandinas, 1369-1382, Lisboa, 2008.

${ }^{14} \mathrm{~S}$ 'il est vrai que celui-ci fut l'on des rares thèmes dans notre historiographie à bénéficier d'une attention positiviste (Quadro Elementar), il faut néanmoins admettre que le médiévalisme portugais reste encore trop attaché à un abordage casuistique de cette question, en privilégiant le facies d'une «politique étrangère» déclinée en termes d'ambassades, des traités et des afliances matrimoniales (A. H. de Oliveira Marques, Maria Margarida Lalanda). Cependant, les nouveaux questionnements posés par l'historiographie récente commencent aussi à frayer maintenant leur chemin aussi chez nous et les travaux d'Armando Martins sur la diplomatie au temps de Ferdinand $\mathrm{I}^{\text {er }}(1367-1383)$ illustrent bien la tendance récente de l'étude de la diplomatie en tant que «pratique diplomatique»; Dans cette conjoncture, le cas des relations diplomatiques entre le Portugal et la Papaute d; Avignon est particulièrement frappant, puisque celles-ci sont normalement abordees d'une façon très génerique dans les syntheses existantes ou de forme très spécifique par le dénombrement de leurs agents formels (listes d'ambassadeurs). Tout ceci découle d'une série de facteurs, dont le manque d'une recherche fondamentale sur la documentation conservée aux Archives Vaticanes, ce qui oblige encore à un travail d'inventaire dont cet article peut constituer un exemple. La bibliographie qui supporte ces idées peut être recueillie au long des notes infrapaginales et dans les tableaux placés à la fin du travail. Il faut ajouter que nous avons utilisé la dernière liste d'ambassadeurs apostoliques disponible, due aux soins de Saul António Gomes (Saul António Gomes, Embalxadores de Portugal junto da Santa Sé, in
} 
la sélection documentaire effectuée au longs des temps dans l'archive de la Couronne lusitanienne ${ }^{15}$. C'est notamment le cas des diplômes lancés dans les registres de chancelleries royaux. Soumis à une reforme pendant les XIV et $\mathrm{XV}^{\mathrm{e}}$ siècles $^{16}$, ils ont résisté au tremblement de terre de 1755 et la plupart est aujourd'hui d'accès facile par leur édition depuis trente ans ${ }^{17}$. Il reste toutefois que les registres pour la période avignonnaise sont, pour la plupart, des registres mis au net qui recensent le plus souvent les droits juridictionnelles de la Couronne, ainsi que les donations et les privilèges qu'elle concéda à des

Dicionário de História Religiosa de Portugal (Carlos Moreira AZEVEDO, dir), vol. II, Rio de Mouro, 2000, p. 103-110) et celle, un peu plus descriptive, d'António Domingues de Sousa Costa, Santa Sé, Portugal e a, in Dicionário de História de Portugal (J. SERRÃO, ed.), [s.1.], 1975 , p. $456-458$.

${ }^{15}$ L'histoire de la Torre do Tombo et son organisation au long des temps a été le sujet de nombreux travaux, dont il faut citer entre autres Pedro de AZEVEDO et António BAIÃO, O Archivo da Torre do Tombo - Sua História, Corpos que o Compõem e Organização, nouvelle édition, Lisboa 1989; Saul António GOMES, Identidade e Memoria na chancelaria Real Portuguesa na Idade Média, in Raízes medievais do Brasil moderno. Actas do Colóquio. 2 a 5 de Novembro 2007 (M. VENTURA, J. VARANDAS, coords.), Lisboa, 2008, p. 67-75; Fernanḍa , O Acesso à informação nos arquivos, thèse de Doctorat, Faculdade de Letras de 1 'Universidade de Porto, 2003. [en ligne: http://ler.letras.up.pt/revistas/index.htm].

${ }^{16}$ Avelino de Jesus da COSTA, A chancelaria Real portuguesa e os seus Registos, de 1217 a 1438, «Revista da Faculdade de Letras [Universidade do Porto] - História», II Serie, XIII (1996), p. 71-101; Judite de FREITAS, Chancelarias Régias Quatrocentistas: produção manuscrita e aproximação político-diplomática.

[en ligne: cepese.up.pt/ficheiros/Judite\%20freitas_Chancelaria.pdf]

${ }^{17}$ Chancelarias Portuguesas: D. Pedro I (A.H. de Oliveira MARQUES, org.), Lisboa, 1982. Chancelarias Portuguesas: D. Afonso IV (A. H. de Oliveira MARQUES, org.), Lisboa, 1990-1992 3 vols; Chancelarias portuguesas: D. Duarte (J. Alves DIAS, org.), Lisboa, 2002. 3 vols en 4 tomos; Chancelarias portuguesas: D. João I (J. Alves DIAS, org.), Lisboa, 2004-2007. 4 volumes en 11 tomes. La publication de la chancellerie d'Alphonse III a été récemment entamée à Coimbra: Chancelaria de D. Afonso III - Livro I (L. VENTURA et A. Resende de OLIVEIRA, eds), Coimbra, 2007. 2 vols. Pendant les années 1960 et 1970 de nombreuses thèses de licence inédites réalisées à la Façulté de Lettres de l'université de cette dernière ville ont transcrit des parties des registres des rois Alphonse II, Alphonse III, Denis et Ferdinand $\mathrm{I}^{\mathrm{er}}$ : Balbina Rodrigues de ALMEIDA, D. Dinis: breve estudo da sua chancelaria: folhas 25-86 (1969); Maria Regina Antunes BÁRTOLO, Documentos da Chancelaria de D. Fernando: 1370-1372: subsídios para o estudo da época Fernandina (1966); Maria Angela Godinho Vieira da Rocha BEIRANTE, Estudo de Alguns documentos da Chancelaria de Dinis. Livro II, fólios 7-57v (1291-1293) (1969); José Tomás Moniz de BRAGA, D. Afonso II: breve estudo da sua chancelaria: folhas 46vo-81vo (1970); Joaquim da Silva CARMONA, Documentos da Chancelaria de D. Dinis. 1287-1289. Subsídios para o estudo da Epoca Dionisina (1968); Maria Eugénia Miranda Marques Couto FARIA, D. Afonso III. Breve Estudo da Sua Chancelaria. Livro 1, Folha 111v - 137v. (1969); Hélder Ferreira Pereira FORTE, D. Afonso II: breve estudo da sua chancelaria: folhas 22-46 vo (1968); Alice Correia GoDINHO, D. Dinis. Subsídios para o estudo da sua chancelaria. Fls 87v-167 (1969); Maria Guilhermina Machado LARANJEIRA, Subsídios para o estudo da chancelaria de D. Afonso III: fls. 62-86v (1969); Laura Oliva Correia LEMOS, Aspectos do Reinado de D. Dinis segundo o Estudo de Alguns Documentos da sua Chancelaria. Livro III. Folhas 81v-102v (1973); Maria Rosa Ferreira MARREIROS, A Administração Pública em Portugal no Reinado de D. Dinis através do Estudo de Alguns Documentos da Sua Chancelaria. Livro III. Folhas 63-81v (1973); Maria Celeste Pato das NEVES, D. Afonso III: breve estudo da sua Chancelaria (1969); Agostinho Amado PATRÍcIO, Estudo da Chancelaria de D. Dinis. Alguns aspectos da sua época. Livro II, fls. $57 v-109$ (1972); Leonor Maria Cabral RAPoso, D. Afonso III e a sua Epoca. Estudo Baseado em Alguns Documentos da Sua Chancelaria. Livro III, Fólios 137v-164v (1970); João Marinho dos SANTOS, D. Dinis: 1289-1291: subsídios para o estudo da sua Cancelaria Livro I fls. $-252 / v-$ 291/v (1972); José Maria nas Neves Cruz e SANTOS, D. Afonso III: subsídios para o estudo da sua chancelaria (1968); Luís Alberto da Silva SOUSA, Subsídios para o Estudo da Chancelaria de D. Dinis. Livro II - Folhas 109v.-141v (1969); Albertina Antonia VILHENA, Estudo sobre a chancelaria de D. Afonso II (1942). Les registres produits pendant ces réformes se retrouvent, quant à eux, encore inédits. 
personnes et des institutions laïques et ecclésiastiques ${ }^{18}$. Le contenu sur des éventuelles ambassades aux papes d'Avignon y est pratiquement nul, peut-être le résultat d'une conception de sauvegarde des instruments de la diplomatie aux antipodes de celle détectable, par exemple, à la chancellerie aragonaise ou ces pièces étaient objet d'un enregistrement secret ${ }^{19}$.

Ainsi, il faut chercher plus d'informations dans la documentation conservée en pièces, longtemps conservée en layettes. Organisée selon une logique thématique ou par type diplomatique, ce fond a souffert d'un réarrangement à la suite dudit tremblement ${ }^{20}$. Pour le cas qui est le nôtre, il intéresse surtout la documentation pontificale conservée dans les «gavetas de bullas (layettes de bulles)», d'où Fr. Francisco Brandão transcrit en 1640 la bulle de concession de privilèges à l'université de Lisbonne datée de $1290^{21}$. Cet arrangement pré-séisme de la documentation royale en pièce a depuis été l'objet de nouvelles classifications sans que l'on sache la degré de disparition entre les documents contenus dans ces layettes et leur dépôt final, aujourd'hui consultable dans un fond justement intitulé Bulles que nous pouvons consulter aisément à la Torre do Tombo.

\footnotetext{
${ }^{18}$ Les typologies de diplômes émis par la chancellerie royale ou par les notaires publics contenus dans ces registres a été reconnue par les études qui s'attardent sur leurs constitution, caractéristiques et contenu: outre les travaux de Avelino de Jesus da Costa et de Júdite Freitas mentionnés ci-dessus, voir Maria Helena da Cruz CoELHO et Armando Luís de Carvalho HoMEM, Origines et évolution du registre de la chancellerie royale portugaise (XIIIe-XV $V^{e}$ siècles), «Revista da Faculdade de Letras [da Universidade do Porto] - História», II ${ }^{\mathrm{e}}$ série, XII (1995), p. 47-76 [en ligne : http://ler.letras.up.pt/uploads/ficheiros/2021.pdf]; eid., Les actes judiciaires de Pierre $I^{e r}$ du Portugal (1357-1366), in La diplomatica dei documenti giudiziari (dai placiti agli acta, secc. XII-XV). Atti del X Congresso Internazionale della Commission Internationale de Diplomatique (Bologna, 12-15 settembre 2001) (G. NICOLAJ, ed.), Roma, 2004, p. 291-293 [en ligne: http://www.archivi.beniculturali.it/DGA-free/Saggi/Saggi 83.pdf] et in Os Reinos Ibéricos na Idade Média. Livro de Homenagem ao Prof. Doutor Humberto Carlos Baquero Moreno (L. Adão da FonsECA, L. AMARAL et M. SANTOS, eds.), vol. III, Porto, 2003, p. $1073-$ 1081; eid., Notas sobre as cartas de justiça na chancelaria dos monarcas portugueses (séculos XIII-XIV), in Svmmvs Philologvs Necnon Verborum Imperator. Colectanea de Estudos em Homenagem ao Académico de Mérito, Professor Dr. José Pedro Machado no seu $90^{\circ}$ Aniversario, Lisboa, 2004, p. 215-231; Isaías da Rosa PEREIRA, Maria Helena da Cruz COELHO, José MARQUES et Armando Luís de Carvalho HoMEM, Diplomatique royale portugaise: Alphonse IV (1325-1357), in Diplomatique Royale du Moyen Age XIII'-XIV siècles. Actes du colloque (J.MARQUES, ed.), Porto, 1996, p. 133-155 [en ligne : http://ler.letras.up.pt/uploads/ficheiros/3825.pdf]; Bernardo de SÁ-NogUEIRA, Apontamentos sobre os livros de registo da chancelaria de D. Dinis «Clio. Revista do Centro de história da Universidade de Lisboa», 16-17 (2007), p. 181188; João António Mendes NEVES, $A$ "Formosa" chancelaria: estudo dos originais da chancelaria de D. Fernando (1367-1383), mémoire de maîtrise en Histoire du Moyen Âge, Faculdade de Letras de l'Universidade de Coimbra, 2005. Le registre et la conservation de la documentation royạle au niveau local fut thème d'un article de Filipa ROLDÃo, Para além da chancelaria : registo e conservação de diplomas dionisinos na administracão régia periférica, «Clio. Revista do Centro de história da Universidade de Lisboa», 16-17 (2007), p. 189-221.

${ }^{19}$ Stéphane PÉQUIGNOT, Enregistrer, ordonner et contrôler: les documents diplomatiques dans les «Registra Secreta» de Jacques II d'Aragon, «Anuario de Éstudios Medievales», 32/1 (2002), p. 435-436. A notre connaissance, cette préoccupation spécifique concernant la documentation royale portugaise médiévale est identifiable seulement dans le contexte de la célébration du traité d'Agreda en 1304. Les documents concernant la médiation que Denis joua dans cet accord entre les royaumes de Castille et d'Aragon furent enregistrés dans un cartulaire déjà publié et connu actuellement comme le Livro das Lezírias de D. Dinis (O Livro das Lezírias d'El Rei Dom Dinis (B. SÁ-NogUEIRA, ed.), Lisboa, 2003.

${ }^{20}$ F. RIBEIRO, O Acesso, p. 101-102.

${ }^{21}$ Fr. Francisco BRANDÃO, Quinta Parte da Monarquia Lusitana, $3^{\mathrm{e}}$ édition (A. RÊGO, ed), Lisboa, 1976, fl. 320 et F. RIBEIRO, O Acesso, p. 101.
} 
Le dépouillement de ce fond doit être complété par les bulles retirées aux divers instituts religieux portugais à la suite de l'extinction des ordres religieux masculins en 1834, une documentation constitutive d'une collection d'organisation chronologique appelée Colecção Especial ${ }^{22}$. Curieusement, le nombre de bulles avignonnaises destinées à la Couronne y est manifestement réduit, lorsque que l'on compare avec toutes les bulles adressées aux rois, aux reines et aux dauphins lusitaniens enrôlées dans les Registra pontificaux. Afin de palier ces lacunes, dont nous n'avons pas d'explication pour le moment, ce sont constituées au long des temps des collections de copies de bulles et de brefs apostoliques conservés à Rome ${ }^{23}$. Celles-ci constituent encore aujourd'hui une source d'information importante, en attendant l'élaboration d'un bullaire portugais en due forme, dont Peter Linehan est à veille de présenter une contribution importante ${ }^{24}$.

Dans cette conjoncture documentaire plutôt défavorable il faut inclure la disparition du gros de la documentation spécifique produite dans le cadre des représentations envoyées par les monarques lusitaniens aux papes à Avignon. En effet, les lettres de créance, de procuration, les instructions royales, les comptes-rendus financiers des voyages ou les rapports de la mission -que l'on peut consulter pour d'autres régions ${ }^{25}$ - ne sont pas représentés dans les archives de la Couronne portugaise actuellement conservées aux Archives Nationales de la Torre do Tombo ${ }^{26}$. Il s'agit

\footnotetext{
${ }^{22}$ Laquelle bénéficia au $\mathrm{XX}^{\mathrm{e}}$ siècle d'une réorganisation dans le but de restituer les pièces $\mathrm{y}$ déposées à leurs fonds d'origine.

${ }^{23}$ Les deux collections de copies de bulles les plus connues sont les Symmicta Lusitanica et les 187 copies ordonnées par le vicomte Carreira constituant aujourd'hui la boîte 27 de la Colecção Especial à la Torre do Tombo (Alexandre HERCULANO, A Symmicta Lusitana, «Archivo Historico Portuguez», vol. I, 11 (Novembro 1903), p. 369-370 et Pedro de AZEVEDO, A colecção do visconde da Carreira "Boletim da Segunda Classe da Academia das Sciências de Lisboa», 8 (1915), p. 183-205). D'autres copies se retrouvent également dans le fonds de la Comissão para a História Eclesiástica. L'une des conséquences que l'ont peut envisager de cette conjoncture documentaire, c'est le nombre très réduit des bulles originales envoyées à la famille royale portugaise pendant la période et conservées actuellement dans les archives nationales. Cela rend insignifiant une étude en règle des procureurs curiaux employés par la Couronne portugaise à partir des mentions au verso desdites bulles, bien que nous n'ignorons par le caractère essentielle de cet abordage pour l'étude que nous envisageons ici. Ce travail peut s'avérer bien plus rentable pour le cas des procurateurs engagés par les institutions ecclésiasstiques portugaises à Avignon via la mise à contribution des centaines de bulles qui leur fut destinées et qui demeurent dans les fonds des institutions monastico-conventuelles et dans la Colecção Especial de la Torre do Tombo.

${ }^{24} \mathrm{Ce}$ bullaire recensera les bulles originales conservées dans les archives ibériques dès 1198 à 1420 , selon les informations fournies par l'auteur.

${ }^{25}$ Une brève typologie de la documentation produite lors des ambassades médiévales fut esquissée par Pau CATEURA BENNȦSSER, Negocier la paz en el siglo XIV, in A Guerra e a sociedade na Idade Média. VI Jornadas luso-espanholas de estudos medievais. 6 a 8 de Novembro de 2008 (M. CoElHO, S. Gomes et A. REBELO, eds.), vol. II, Coimbra, 2009, p. 23-28. Nous pensons notamment aux registres anglais et aux rapports de missions faites par les ambassadeurs aragonais à leur roi conservés aux Arrchives de la Couronne d'Aragon (K. PLÖGER, England and the Avignon Popes, p. 10-12; Acta Aragonensia; Quellen zur deutschen, italienischen, französischen, spanischen, zur Kirchen- und Kulturgeschichte aus der diplomatischen Korrespondenz Jaymes II (Heinrich FINKE, ed.), Berlin-Leipzig, 1908-1922. 2 vols. [en ligne: http://www.archive.org/details/actaaragonensiaq01finkuoft et .. 02finkuoft].

${ }^{26} \mathrm{~L}$ 'étude de la question pour le $X \mathrm{VV}^{\mathrm{e}}$ siècle se retrouve facilité, notamment par l'analyse des registres financiers de la royauté qui mentionnent des paiements aux ambassadeurs et l'existence de formulaires qui permettent d'attester la géographie des relations royales à partir des destinataires de ces lettres (Maria José FARO et Jorge FARO, Embaixadas enviadas pelos reis de
} 
certainement d'une disparition plutôt que d'une absence. En effet, lors des cortès de 1385, le légiste João das Regras pouvait encore, dans le cadre de son argumentation pour prouver la légitimité du maître de l'ordre d'Avis à accéder au trône, produire un rotulus d'instructions signé par le roi et son conseil destiné à son ambassadeur à Avignon en $1361^{2 \mathcal{T}}$.

Il est plausible que cette documentation, normalement destinée à la Curie, soit restée à Avignon. C'est ce qui suggère un inventaire non-daté conservé aux Archives Vaticanes sous la cote Registra Avenionensia (RA) 91, aux folios 303-315v. Faisant le décompte des biens d'un évêque, très probablement Martim Afonso de Brito, nommé pour le siège d'Évora en 1341 lors de son séjour à la curie, y sont dénombrées deux arches contenant des documents royaux dont le contenu remet aussi pour des lettres de créance et des instructions pour les ambassadeurs (Item um caderno pequeno de papel de informações para o papa que lhe haviam de fazer os mensageiros do rei) ${ }^{28}$. Il s'agit des documents qui, avant l'arrivée à la curie de l'ambassadeur (Martim Afonso de Brito?), étaient sous la garde de Gonçalo Peres Raposo ${ }^{29}$, dont on sait qu'il restait à la Curie dans la qualité de procurateur d'individualités lusitaniennes $^{30}$. Plus que toutes les incertitudes qui entourent ce docu

Portugal de 1415 a 1473. Subsídios documentais, in Actas do Congresso internacional de História dos Descobrimentos, vol. III, Lisboa, 1961, p. 249-270 et Jorge FARO, Receitas e Despesas da Fazenda Real de 1384 a 1481, Lisboa, 1965, p. 74-82; A. H. de Oliveira MARQUES et João José Alves DiAs, Portugal na Europa Medieval, in Actas dos V Cursos Internacionais de Verão de Cascais, vol. 2: Pequenos e Grandes Estados, Cascais, 1999, p. 29-44.

${ }^{27}$ Fernão LOPES, Crónica de D. João I (H. Moreno et A. SÉRGIO, eds), vol. I, Lisboa, [s.d.], chap. CXC, p. 416-417. Sur l'authenticité de cette source voir António BRÁSIO, A argumentaçẫo de Joâo das Regras nas cortes de Coimbra "Anais da Academia Portuguesa da História», XI (1961), p. 207-209 et MPV, vol. II, p. CCCLXXII-III. La signature des instructions par les membres do conseil royal' aide à justifier le recrutement des ambassadeurs et atteste la participation de cette institution dans les affaires diplomatiques du royaume. Comme les chroniques portugaises prennent le plus souvent la vision «royale» des affaires, elles peuvent être mises à contribution dans ce sujet. En plus de contenir des documents entretemps disparus, elles mentionnent parfois ces ambassades au pape. Toutefois, il n'y pas de systématisation et lẹs informations passibles d'utilisation demeurent de qualité variable. Sur cette question, voir António Resende de OlIVEIRA, Comunicar no Portugal Medieval: os relatos dos cronistas, in As Comunicações da Idade Média (M. CoElHO, ed.), Lisboa, 2002, p. 43.

${ }^{28}$ ASV, Reg. Aven. 91, fl. 303v, 315.

${ }^{29}$ ASV, Reg. Aven. 91, fl. 311.

${ }^{30}$ Notamment du curial Vasco Martins, bientôt évêque de Porto et puis de Lisbonne, dont il assurait l'administration de son hospicium avignonnais en 1333. ASV, Reg. Aven. 42, fil. 302v; Maria Helena da Cruz CoELHo et Anísio Miguel de Sousa SARAIVA, D. Vasco Martins, vescovo di Oporto e di Lisbona: una carriera tra Portogallo ed Avignone durante la prima meta del Trecento, in A Igreja e o Clero Português no Contexto Europeu/The Church and the Portuguese Clergy in the European Context, Lisboa, 2005, p. 123, note 36. Gonçalo Peres est chanoine en expectative de prébende à Guarda et recteur de f'église paroissiale de Saint-Jacques de Bidirido (diocèse de Porto) avant le 30 mai 1331, data à laquelle il obtient une provision apostolique dans une demi-prébende du chapitre de Viseu. Moins d'un an plus tard 11 joint à ses bénéfices le rectorat de la collégiale de Saint-Jacques d'Evora (1332, août 6). Il agira aussi en 1333 et 1342 en tant qu'exécuteur apostolique de provisions bénéficiales (LCJXXII, n ${ }^{\circ} 53710,57974,59702$, 61745; ASV, Reg. Aven. 57, fl. 16v-17v). En mai 1343, désigné de procureur de ce même Vasco Martins, maintenant évếque de Lisbonne, il sollicite le canonicat et la prébende d'Evora, peu avant que ce prélat quémande lui-même en faveur de son clerc - qu'il qualifie maintenant de scribe originaire de Braga - une expectative de prébende dans le chapitre de Braga ( $M P V$, vol. $\left.\mathrm{I}, \mathrm{p} .9, \mathrm{n}^{\circ} 11 ; \mathrm{p} .17-18, \mathrm{n}^{\mathrm{O}} 24\right)$. Son rectorat de Saint-Jacques est attesté dans les sources locales entre au moins les années 1334 et 1344 (Biblioteca Pública de Evora, Pergaminhos Avulsos, liasse $22, n^{0} 7$ [daté de 1317, ce qui peut indiquer peut-être une mauvaise datation du, document], $15,20,22,46$ et liasse 24, n $^{\circ} 52,54,86$ (toutes les informations sur le rectorat à Evora furent prises dans les sommaires de la documentation en ligne sur le site du projet Fonds documentaires 
ment ${ }^{31}$, l'important demeure que la documentation nécessaire aux agents diplomatiques portugais à Avignon pouvait rester sous place, afin de les aider dans leurs démarches auprès de la Curie.

Au contraire de la «pauvreté» typologique de la documentation royale portugaise pour le thème qui est le nôtre, c'est à l'Archivio Segreto Vaticano (ASV), dans les registres de la chancellerie (Registra Avenionensia et Vaticana) et dans les suppliques apostoliques, qu'il est possible de retirer le plus d'informations sur le sujet à l'étude, soit par l'indication dans les litterae curiales de l'arrivée et du contact établi avec les ambassadeurs, soit dans les suppliques que recensent leurs demandes bénéficiales ou gracieuses en faveur de leur famille et de leurs dépendants ${ }^{32}$. Cette documentation, complétée avec les enregistrements de nature fiscale relative à des paiements et à la gestion de droits à la Chambre ${ }^{33}$ et les pièces de nature diverse (procurations notamment) sauvegardées dans le fond Instrumenta Miscellanea ${ }^{34}$, permet une meilleure vision du large spectre de ces ambassades dont il est nécessaire de recenser les rythmes et les intervenants.

\section{LES REPRÉSENTATIONS DE LA COURONNE: LES AMBASSADES FORMELLES}

Les affaires de la Couronne présentées et poursuivies à la Curie avignonnaise appelaient à la constitution d'un ensemble varié de représentants, selon qu'il s'agissait de l'obtention d'un bénéfice ou d'une grâce, d'une négociation sur une problématique déterminée ou la poursuite sur place d'un procès dans cadre des tribunaux apostoliques. Dans les types de représentation discernables dans les sources, la plus représentative concerne les ambassades envoyés à la Curie par le roi portugais (et dans un degré moindre la reine). Celles-ci sont les plus formelles et se distinguent par le mandat de représenta-

d'institutions du Sud (FUNDIS) hébergé dans http://fundis.cidehus.uevora.pt, à l'exception du document de la liasse $24, n^{\circ} 86$ dont les informations nous furent gentiment communiquées par Joaquim Serra, à qui nous remercions vivement).

${ }^{31}$ Cet important document est en voie de publication par Anísio Saraiva. En ce sens, l'hypothèse d'identification proposée est uniquement indicative et elle fut esquissée à partir de la lecture de la source. Nous remettons les lecteurs pour ce travail en cours d'elaboration par ledit auteur pour la critique en termes de datation, de contenu et de conditions d'élaboration.

${ }^{32}$ Ces lettres furent l'objet d'une édition par l'École Française de Rome par les analyses ou l'édition in extenso, bien qu'il y ait encore de nombreuses lettres inédites, notamment celles de Jean XXII pour les pays autres que la France et d'Urbain V. Voir la récente mise au point de Laurent Vallière à publier dans la revue Lusitania Sacra. Les suppliques entre 1342 et 1366 concernant le Portugal furent éditées de façon systématique dans le premier volume des MPV.

${ }^{33}$ Sections Collectoriae, Introitus et Exidus, Obligationes et Solutiones du Fondo Camerale dont la plupart des informations furent publiées dans le cadre de la collection Vatikanische Quellen zur Geschichte der päpstlichen Hof- und Finanzverwaltung 1316-1378. L'importance du fond Obligationes et Solutiones pour le repérage des procureurs à la Curie a été très bien mise en évidence par Pierre-Marie BERTHE, L'enregistrement à la curie pontificale au XIV siècle in Offices, écrit et papauté (XIII ${ }^{e}-X V I I^{e}$ siècle) (Armand JAMME et Olivier PONCET, eds.), Rome, 2007 , p. $685-704$

${ }^{34}$ Dont certaines pièces inédites intéressant le Portugal au XIV ${ }^{\mathrm{e}}$ siècle et qui demeurent, à toute fin pratique, inconnues de la médiévistique lusitanienne. 
tion qui est donné par le monarque à ces ambassadeurs normalement pour des sujets préétablis sous forme de lettre de procuration ou de créance (letra de crença $)^{35}$. Celles-ci devaient être claires et spécifiques afin de rendre impossible une action dilatoire pour motif d'une procuration insuffisante ${ }^{36}$.

Pour cette représentation «officielle» du roi il faudrait donc des hommes de qualité. Une qualité certainement sociale qui ouvrait les ambassades aux nobles, c'est-à-dire, à un groupe privilégié, reconnu par leur rôle traditionnel d'appui à la monarchie et détenteur des liens familiers ou de clientèles très souvent extensibles au-delà des frontières physiques du royaume. Mais aussi une qualité technique liée au service du monarque dans les structures centrales de gouvernement comme la chancellerie et les divers tribunaux royaux ou liée à l'expérience dans la conduction des affaires de l'Église par les serviteurs du monarque appartenant à l'état ecclésiastique ${ }^{37}$. Dans une activité où l'information se mélangeait avec la communication, ces spécialistes de l'oratoire, de la manipulation de la langue latine et du culte de l'oratoire se rendaient très utiles au moment d'exprimer les messages royaux de forme éloquente ${ }^{38}$.

Pendant le règne de Denis Ier, l'activité diplomatique avec la Curie devient plus visible à la suite du concile de Vienne réalisé entre 1311 et 1312 . Il est très probable que pendant cette période les relations entre la Couronne et la Papauté aient été assurées par les anciens clercs du roi qui maintenant y représentaient leurs diocèses et qui eurent un rôle déterminant dans le réarrangement du corps épiscopal lusitanien dicté par la mort de l'archevêque de Braga Martinho Peres de Oliveira en 1313 ou dans l'introduction de la

${ }^{35}$ Sur ces lettres, voir Pau CATEURA BENNÁSSER, Negocier la paz, p. 23-26.

${ }^{36}$ Dans une ambassade portugaise en Angleterre en 1325, le roi Édouard II mentionne que le porteur des lettres de créance du monarque lusitanien, Pedro de Lara, n'était pas mandaté pour traiter des contrats de mariage entre les deux couronnes. Il fallait que le monarque portugais lui fasse envoyer des ambassadeurs spécifiques à cet effet. Visconde de SANTAREM, Quadro elementar das relaç̃es políticas e diplomáticas de Portugal com as diversas potências do mundo desde o princípio da monarquia portuguesa até aos nossos dias, vol. XIV, Paris, 1853, p. 24.

${ }^{37}$ Guillaume Mollat, La diplomatie pontificale au XIV e siècle, in Mélanges d'histoire du moyen âge dédiés à la mémoire de Louis Halphen, Paris, 1951, p. 507; K. PLÖGER, England and the Avignon Popes, p. 65-71. Pour certains de ces agents, une ambassade était le moment de choix pour acquérir un nouveau statut ou une nouvelle charge auprès du service de la Couronne. Rappelons l'accès de Pedro do Sem à la charge de chanceliêr d'Alphonse IV très vraisemblablement avant son envoi à Avignon en 1334. L exemple le plus paradigmatique de cette question demeure l'adoubement du chancelier Lourenco Eanes Fogaça en 1383, lequel «emtõ na See o Meestre fez cavalleiro amte que partisse» selon le chroniqueur Fernão Lopes (F. LOPES, Crónica de D. João, vol. I, chap. XLVII, p. 95). Sur l'ambassade de Fernão Afonso de Albuquerque et Lourenço Eanes Fogaça en Angleterre, voir spécifiquement Armando Luís de Carvalho HoMEM, Diplomacia e burocracia nos finais da Idade Média: a propósito de Lourenço Anes Fogaça, Chanceler-Mor (1374-1395) e negociador do tratado de Windsor, in Estudos e Ensaios em homenagem a Vitorino Magalhães Godinho, Lisboa, 1988, p. 217-228 et Tiago Viúla de FARIA "Por proll e serviço do reino? O desempenho dos negociantes portugueses do Tratado de Windsor e suas consequências nas relaçốes com Inglaterra (1384-1412), in A Guerra e a sociedade na Idade Média. VI Jornadas luso-espanholas de estudos medievais. 6 a 8 de Novembro de 2008 (M. CoElHo, S. Gomes et A. REBElo, eds.), vol. II, Coimbra, 2009, p. 209-227, ainsi que la bibliographie y citée.

${ }^{38} \mathrm{La}$ qualité de l'ambassadeur est très souvent mentionnée par les lettres apostoliques de créance ou dans les lettres contenant les réponses du pape lorsqu'elles étaient écrites. Celles-ci pouvaient être codées comme avance Guillaume Mollat au sujet de Jean XXII et de Robert de Naples (G. Mollat, La diplomatie médiévale, p. 508). 
fiscalité apostolique après les promesses de subside qu'ils y firent à Clément $\mathrm{V}$ au nom du clergé portugais ${ }^{39}$.

Les thèmes qui parsemèrent la suite du règne dionysien furent de façon à nécessiter un courant soutenu de diplomatique. En premier lieu, la destination à donner aux biens portugais de l'ordre du Temple dissoute lors dudit concile. Ce procès complexe, initié en 1312 et culminant sept ans plus tard avec la naissance de l'ordre de Christ et sa réception de l'ancien patrimoine templier, a obligé le roi à «envoyer, par de nombreuses fois, à la curie de Rome, ses procureurs et messagers $»^{40}$. Il faut dire que la dernière période des négociations fut déjà menée à la curie de Jean XXII dans le climat d'instabilité survenu, à partir de 1317, par la question de l'existence du maître portugais de l'ordre de Saint-Jacques et, surtout, par la dégradation des relations entre le roi et le dauphin Alphonse ${ }^{41}$. Il est possible penser que les ambassades successives à la Curie des nobles Vicente Eanes César et João Lourenço de Monsaraz s'inscrivent dans le cadre de la perpétuation dans le temps de ces questions ${ }^{42}$. Leur expérience et leur connaissance des méandres de la Curie garantissaient au roi le plus de chances dans leur désir l'éviter le passage aux Hospitaliers des biens du Temple et de garantir que la partie portugais de l'ordre de Saint-Jacques aurait pu bénéficier du commandement d'un maître ${ }^{43}$.

Cette même spécialisation est visible dans les ambassades de Manuele Pessagno. Génois, frère d'Antonio Pessagno, conseiller du roi anglais, sa nomination comme amiral du roi portugais en 1317 doit se situer dans la stratégie de renforcement de la marine lusitanienne voulue par Denis ${ }^{44}$. Et, de

\footnotetext{
${ }^{39}$ Mário FARELO, Les clercs étrangers au Portugal durant la période de la papauté avignonnaise: un aperçu préliminaire, «Lusitania Sacra» (sous presse).

${ }^{40} \mathrm{C}$ 'est une des raisons évoquées par le premier-maître de l'ordre, Gil Martins, pour faire donation au roi des rendements de ces biens pendant le temps qu'ils furent sous l'administration dionysienne (MPV, vol. I, p. XLVI).

${ }^{41}$ La seconde question a été de loin beaucoup plus traitée par l'historiographie. Les travaux principaux sur l'une et l'autre sont recensés dans notre tableau I.

${ }^{42}$ Sur le premier, voir Armando Luís de Carvalho Homem, O Desembargo Régio (1320 1433), Porto, 1990 p. 392-393. Ce João Lourenço fut peut-être l'homonyme attesté comme officier du roi entre 1320-1324 et 1328-1332 (ib., p. 344-345).

${ }^{43} \mathrm{Il}$ est possible perspectiver que l'aboutissement favorable à Portugal de la question du Temple n'a pas été sans relation avec les quatre mille florins envoyés par le monarque au pape dans l'ambassade de l'amiral Manuele Pessagno à la fin de 1317 et le début de 1318. Cette somme a peut-être aidé à débloquer l'affaire et a permis qu'en août de cette année le monarque ait été en mesure de nommer les ambassadeurs João Lourenço de Monsaraz et Pedro Peres pour achever les négociations. La lettre de Jean XXII au roi Denis de remerciement de cette somme se retrouve en copie dans Arquivo Nacional da Torre do Tombo [dorénavant ANTT], Bulas, m. 68, n. 59 et fut publiée dans Fernando Félix LOPES, Santa Isabel de Portugal. A larga contenda entre el-rei D. Dinis e seu filho D. Afonso, in id., Colectânea de Estudos de História e Literatura, vol. III: Santa Isabel e outros estudos, Lisboa, 1997, p. 97.

${ }^{44} \mathrm{La}$ fratrie des Pessagnos a été sujet de diverses études, notamment M. F. E. G. da SILVA, PESSANHA, Manuel (séculos XIII-XIV), in Dictionário de História de Portugal, vol. V: ParóquiaSintra (J. SERRÃO, ed.), [s.1.]: 1975, p. 73-74; Fátima Regina FERNANDES, $O$ conceito de estrangeiro em Portugal na baixa Idade Média: um estudo de caso, «Revista de Ciências Históricas» 14 (1999), p. 93-120; ead., Los genoveses en la armada portuguesa: Los Pessanha, "Edad Media. Revista de Historia», 4 (2001), p. 199-226; Gabriela AIRALDI, Due fratelli genovesi: Manuele e Antonio Pessagno, in Estudos em homenagem ao Professor Doutor José Marques (N. ALVES, M. CUNHA et F. RIBEIRO, eds.), vol. II, Porto, 2006, p. 139-140; Gianluca PAGANI, I Boccanegra e $i$ Pessagno tra la pace e la guerra nella penisola ibérica del
} 
ce fait, les ambassades qu'il mène à Avignon en 1317-1318 et, surtout, celle de 1320, représente un pas en avant dans ce but. En effet, la concession triennale des décimes ecclésiastiques que Jean XXII y fit alors en faveur de Denis, tout en permettant résoudre le problème causé par la collecte de la décime sexennale décrétée par Clément $\mathrm{V}$ lors du concile de Vienne, tient pour objectif principal la constitution d'une flotte ${ }^{45}$.

De plus, la présence curiale de ces nobles était la plupart du temps accompagné par les clercs du roi. Désignés aussi pour des affaires spécifiques comme la création de l'ordre de Christ ou la demande de dispense de mariage pour le dauphin Pierre, leur action se distingue par leur permanence à Avignon. Cette manutention leur permettait de se familiariser avec les méandres curiaux, ce qui ne pouvait que constituer un atout pour les affaires du roi et, surtout, pour l'avancement de leur propre carrière à l'instar du trio d'individus à l'œuvre vers la fin du règne dionysien : Pedro Peres ${ }^{46}$, Gonçalo Pereira $^{47}$ et Vasco Martins ${ }^{48}$.

quattordicesimo secolo, in A Guerra e a sociedade na Idade Média. VI Jornadas luso-espanholas de estudos medievais. 6 a 8 de Novembro de 2008 (M. Cruz COELHO, S. GOMES et A. REBELO, eds.), vol. I, Coimbra, 2009, p. 471-478 qui recensent la bibliographie antérieur lui concernant. Sur les raisons de cette nomination, Fr. Francisco Brandão affirme que cette concession tient à la base la volonté royale à soustraire l'amirauté à l'influence de l'infant Alphonse (Fr. Francisco BRANDÃO, Sexta Parte da Monarquia Lusitana, $3^{\mathrm{e}}$ édition (A. RÊGO, ed), Lisboa, 1980, p. 235). Or, il ne faut pas oublier le poids des solidarités familiales. Il est à peu près sûr que son frère Antonio était à Avignon dans la qualité d'ambassadeur du roi anglais au même temps que les envoyés portugais chargés de choisir le nouveau amiral (la référence du séjour avignonnais d'Antonio dans Barbara BOMBI, Il Registro, di Andrea Sapiti, procuratore alla curia avignonese, Roma, 2005, p. 39, n. XXV). Le fait qu'il fut aussi choisi, par ces liens avec l'Angleterre se prouve par les lettres de recommandation émises par le roi Edouard III le 24 juillet 1332, l'une destinée à Alphonse IV en sa faveur et de son fils Carlos et l'autre à Lopo Fernandes Pacheco, pour que ce dernier concède toutes les grâces qu'il peut à la famille Pessagno (V. SANTARÉM, Ouadro Elementar, vol. XIV, p. 27-28). Sensiblement à la même époque, un fils inconnu de Manuele, Gabriel, obtient la provision apostolique d'un canonicat et d'une expectative de prébende dans le chapitre de Lisbonne (LCJXXII, $\mathrm{n}^{\circ}$ 58533). Cette liaison très proche de la famille avec la Couronne anglaise aide à expliquer la nomination de Manuele pour l'ambassade en Angleterre en 1326, faisant de lui l'un des rares ambassadeurs du roi Denis qui réussirent à transiter au service d'Âlphonse IV.

${ }^{45}$ Descobrimentos portugueses, p. 133-139.

${ }^{46} \mathrm{Il}$ a été clerc du roi et membre de son officialité en tant que auditeur des faits royaux entre 1313 et 1317 . Passé à Avignon l'année suivante, il va profiter de ce séjour pour consolider la condition de chanoine de Coimbra et de Porto par l'obtention -coup sur coup- en 1319 des provisions apostoliques dans des canonicats et prébendes à Lisbonne, Braga, Coimbra et une expectative de dignité dans ce dernier chapitre. Le 27 mai 1321 il ajoute la provision du canonicat et expectative de prébende à Evora, six mois avant d'obtenir une exemption de résidence pour trois ans parce qu'il résidait à la curie. Vers lạ fin de l'année suivante il garantit la nomination à la doyenneté de Porto, lorsque Gonçalo Pereira accède à l'évêché de Lisbonne. Entretemps, il avait jeté son dévolu sur la doyennetẻ de Coimbra dont il était alors en litige à la Curie, après avoir bénéficié de ces rendements dès, au moins, l'an 1321. Finalement il se voit confirmer les lettres de collation à cette doyenneté et rẹlaxer de toutes les sanctions ecclésiastiques dont il a encouru lors du litige pour la doyenneté coimbraise avec Aymeric de Crégols. LCJXXII, n ${ }^{\circ} 9005$, 9007, 9985, 13479, 14024, 13477, 13478, 16641 et 19204.

${ }^{47} \mathrm{~L}$ 'un des plus importants et influents ecclésiastiques portugais de la première moitié du XIV siècle, il a été clerc de Denis entre les années 1314 et 1322. A Ta curie lors de la première de ces dates afin de se défendre de l'accusation portée contre lui sur une accumulation illégale de bénéfices, il y retourne en 1320 pour combattre les diffamations du roi par l'évêque de Lisbonne. Il reste intermittemment à la curie jusqu'en 1324. C'est là qu'il a reçu la nouvelle de l'élection qu'une partie du chapitre d'Evora a fait à son égard, de même que c'est là qu'il accepte la nomination apostolique en sa faveur à l'évêché de Lisbonne. Il obtiendra la première dignité ecclésiastique séculière du royaume -l'archevêché de Braga- dès 1326 qu'il maintiendra jusqu'à sa mort en 1348. D. Rodrigo da CUNHA, Primeira parte da Historia ecclesiastica dos arcebispos de Braga, e dos santos, e varoes illustres, que florecerão neste arcebispado, Braga, 1636, p. 176 190; ID., História Ecclesiastica da Igreia de Lisboa. Vida, e acçoens de sevs prelados \& varões 
Les plus de trente ans de gouvernement d'Alphonse IV (1325-1357) assistèrent à la manutention de cette représentation formelle. La cadence des ambassades de la Couronne portugaise, évaluée pour cette période au ratio d'une ambassade chaque vingt mois ${ }^{49}$, est indicatrice d'une régularité comparable en nombre à celles envoyées à ses voisins ${ }^{50}$. Tout comme pour le règne antérieur, les questions qui ont suscité ces ambassades demeurent assez typifiées, le plus souvent autour des demandes de dispense de mariages pour les membres de la famille royale $(1326,1329,1331,1334$ ?, 1345, 1353) et de concession de décimes ecclésiastiques $(1325,1329,1332,1340,1345$, $1347,1355)$. Ce sont bien entendu des thèmes qui relèvent en premier lieu des attributions exclusives de la Papauté, mais aussi du déploiement au Portugal des activités ecclésiales. En ce sens, le recours à la Papauté dans le cas des droits de patronage (1327) ou la provision d'évêques $(1325,1356)$ s'inscrit dans cette dialectique de relations entre un pouvoir royal attentif à l'opportunité de resserrer son emprise sur le monde ecclésiastique et le pouvoir spirituel toujours irréductible aux attentats à ses libertés et immunités.

Dans cette conjoncture, finalement assez stéréotypée, la note dissonante se trouve dans les démarches diplomatiques déroulées pendant la guerre luso-castillane de $1337-1339^{51}$. Plus qu'une guerre entre voisins, ce conflit signifia pour la Papauté une brèche dans la ligne de défense qui constituait les états ibériques à l'avancement des musulmans en Occident. L'importance de cette question pour le pouvoir apostolique, visible dans son argumentation, dicta l'envoi du légat Bernard d'Albi, médiateur pour la résolution du conflit ${ }^{52}$. Tout en réduisant l'étendue géographique de cette activité - puisque le légat était sur place- il faut penser que l'activité diplomatique se trouva majoré par la nécessité de convier les messages échangées entre les parties. A cet effet, les ambassades recensées pendant cette période n'ont certes constitué qu'une fraction de l'activité diplomatique

eminentes em santidade, que nella florecerão, Lisboa, 1642, fl. 238-241; Maria Helena da Cruz COELHO, O arcebispo D. Gonçalo Pereira: um querer, um agir, in IX centenário da Dedicacão da Sé de Braga. Actas do Congresso Internacional. Vol. II/1, Braga-Lisboa, 1990, p. 389-463.

${ }^{48}$ Figure très proche de Goncalo.Pereira, dont il fut procureur à diverses reprises, il a été clerc dionysien entre 1315 et 1320 . Â Avignon dès au moins l'année 1321, il sera l'un des plus influents portugais à la curie jusqu'en 1334. Il a été évêque de Porto (1328-1342) et de Lisbonne (1342-1344). Sa biographie sera disponible sous peu due aux soins d'Anísio Saraiva. Pour l'instant il faut consulter M. COELHO et A. SARAIVA, D. Vasco Martins, p. 119-136.

${ }^{49}$ Chiffre calculé à partir des ambassades recensées dans notre Tableau I.

${ }^{50}$ A. MARQues, Portugal na Crise, p. 329.

${ }^{51}$ Celle guerre est la seule que le roi Alphonse IV maintient pendant tout son règne avec un autre état chrétien. La mise au point du déroulement de ce conflit a été fait récemment dans $\mathbf{M}$. MARTINS, A guerra esquiva, p. 19-80.

${ }^{52}$ Marie-Claude MAHAUT, Le rôle pacificateur du papa Benôt XII dans le conflit de la Castille avec le Portugal (1327-1340), in La Guerre et la paix au Moyen Age. Actes du 101 Congrès Nationale des Sociétés Savantes (Lille, 1976), Paris, 1978, p. 227-230, 233, 235. Le roi français y a envoyé un nonce, l'archevêque de Vienne, substitué en cours de route par son frère. 
dont il est possible d'imaginer l'étendu et la variété dans le déjà mentionné registre RA $91^{53}$.

Pour ce qui est des agents diplomatiques, Alphonse IV a suivi la stratégie de son père dans la manutention de l'équilibre entre les ambassadeurs reconnus par leur souche nobiliaire ou par leur prééminence technique. S'il existe une quelconque innovation dans l'agissement royal, il faut la situer au niveau de la confiance témoignée roi envers les légistes qu'il fit promouvoir à son officialité et dont certains le représentèrent à Avignon à l'instar de Maître João das Leis en 1345 et du beau-frère de celui-ci, João Afonso, sept ans plus $\operatorname{tard}^{54}$. Ces derniers faisaient donc partie d'un corps d'officiers reconnus par la proximité et la confiance que leur fait le monarque, datée pour la plupart du temps de la guerre civile de 1319-1324 et incarnée, entre autres aspects, dans la distinction octroyée par une appartenance au Conseil du roi. Cela pourrait aider à expliquer pourquoi des hommes de la qualité de Lopo Fernandes Pacheco et de Lourenço Gomes de Abreu ${ }^{55}$ ont été initiés aux activités diplomatiques dès le début du règne et se maintiendront les diplomates les plus importantes du monarque pendant les quinze années suivantes, comme en témoigne le nombre d'ambassades registrés dans notre Tableau II. Cela explique, de plus, que la «réutilisation» d'antérieurs ambassadeurs dionysiens semble plutôt rare. Outre Estêvão da Guarda, dont les notices de ses missions diplomatiques furent recensées par Armando Luís de Carvalho Homem et par Miguel Gomes Martins ${ }^{56}$, le cas de Manuel Pessagno semble s'inclure dans une conjoncture spéciale. En effet, son

\footnotetext{
${ }^{53}$ Les registres apostoliques copient diverses lettres sur ce conflit, notamment en relation avec la légation de l'évêque de Rodez. Les chroniques portugaises y ajoutent des bulles traduites. Ce registre $R A 91$ fait l'inventaire, quant à lui, dẹs pièces destinées vraisemblablement au travail des ambassadeurs portugais à la Curie, dont certaines sont inconnues et disparurent entretemps: «Item uma carta com selo pendente do cavalo del rei em que fazia seus procuradores Goncalo Vasques de Azevedo e Lourenco Gomes de Abreu em razão da guerra que havia com el rel de Castela» (fl. 313); «Item um instrumento grande da resposta que èl rei de Portugal deu ao bispo de Rodes em razão da guerra» (fl. 314); «Item outro instrumento por mão de Martim Esteves, tabelião de Coimbra em que se continha o traslado do instrumento da trégua que foi feita por Lopo Fernandes, senhor de Ferreira e por Fernao Rodrigues, de Villa de Lobos; Item um instrumento por mao de Lourenço Martins, tabeliao geral em que se continha que o bispo de Rodes publicou as letras do papa ao rei de Portugal; Item outro instrumento feito por mão de Mestre Geraldo em que era conteúdo como o bispo de Rodes fazia algumas requestas a el rei de Portugal; Item outro instrumento da resposta que el rei de Portugal dez ao bispo de Rodes em razão dos benefícios; Item outro instrumento em razão da resposta que el rei deu ao bispo de Rodes em razão da guerra feito por mão de Girạldo Alberti e de Domingos Martins Regado?»(fl. 314v); «Item um cạderno pequeno de papel de informacoes para o papa que lhe haviam de fazer os mensageiros do rei; Item um livro de pergaminho feito por mão de Martim Esteves, tabelião de Coimbra em que era conteúdo o traslado da resposta que el rei de Castela deu a Pedro Afonso, sobrinho do bispo de Coimbra; Item um quaderno em que allegarom doutores em razão da guerra Dante el rei de Portugal e o de Castela; Item um instrumento em tem 5 rois por mão de Lourenço Martins, tab. Geral em Portugal em razão da resposta que el rei fez ao bispo de Rodes» (fl. 315). L'article d'Anisio Saraiva cherchera à dater les documents dont nous connaissons l'existence actuelle.

${ }^{54}$ Voir les Tableau I et II.

${ }^{55}$ Fátima Regina FERNANDES, Os Abreu - uma família em busca do estabelecimento na segunda metade do século XIV, «Revista de Ciências Históricas», 12 (1997), p. 147-154 (qui n'aborde pas la biographie de cet ambassadeur).

${ }^{56}$ A. HomeM, O Desembargo, p. 297 et Miguel Gomes MarTins, Da Esperança a $S$. Vicente de Fora: Um percurso em torno de Estêvão da Guarda, «Cadernos do Arquivo Municipal [Lisboa]» 3 (1999), p. 10-60 (maxime 57); Mário FARELO, A oligarquia camarária de Lisboa (1325-1433). Thèse de doctorat en histoire médiévale, Faculdade de Letras de l'Universidade de Lisboa, 2008, p. 380-382.
} 
ambassade en 1326 servant à conclure une alliance matrimoniale avec l'Angleterre doit se lire, comme l'on a vu, à la lumière des liaisons familières que Manuel maintenait avec ce royaume, où il possède un frère conseiller du roi $^{57}$.

Au demeurant, l'ambassadeur par excellence du règne alphonsin fut le déjà dit Lopo Fernandes Pacheco. Dans la qualité du plus influent et le plus proche conseiller D. Alphonse IV, il a été présent dans les grands événements du règne et bénéficia d'une projection étrangère, puisque c'est lui qui a reçu la rose d'or matérialisant la reconnaissance à la curie du rôle portugais dans l'arrêt de l'offensive musulmane en sol péninsulaire chrétien à la suive de la bataille du Salado ${ }^{58}$. Après sa mort en 1349, les ambassadeurs nobles du roi perdurèrent dans leurs missions à Avignon, maintenant avec des individus de moindre projection ${ }^{59}$.

En ce qui concerne les clercs nommés pour les missions diplomatiques à Avignon, ils attestent une grande expérience des négoces curiaux dont Rui Domingues peut constituer un exemple probant ${ }^{60}$. Bien que celle-ci soit une des raisons principales d'une ou d'autre nomination, il faut avoir à l'esprit la force de la conjoncture. En effet, les ambassades de clercs comme Martim Afonso de Brito peuvent illustrer la variété de justifications possibles pour une telle nomination, allant de la réponse à un procès, la demande de bénéfices mineurs et même la quête d'un évêché6 ${ }^{6}$. Ce sont probablement aussi des coïncidences conjoncturelles - la poursuite à la curie des affaires personnelles ou de ses monastères par exemple - qui expliquent le recours ponctuel au service de réguliers, comme l'abbé de Tarouca, recensé dans la documentation aragonaise en $1330^{62}$

Dans cette même veine de pensée, il faut croire que l'envoi d'officiers royaux peut aussi se justifier par ce leitmotiv conjoncturel. Malheureusement, les évidences sont rares pour bien connaître les raisons qui ont amené Geraldo Esteves, auditeur du roi ou João Afonso à se déplacer à la Curie, outre que pour des motifs d'avancement bénéficial de leurs familles. Peut-être derrière le choix de ces officiers se cachait un procès dont leur expertise était requise pour bien défendre les intérêts de la Couronne comme suggère l'éventuel rôle

${ }^{57}$ Voir supra

${ }^{58}$ Vanda LOURENÇO, Lopo Fernandes Pacheco: um valido de D. Afonso IV «Estudos humanísticos. História», 5 '(2006), p. 49-69 publié aussi dans «Medievalista», 2 (2006), p. 1-19. [en ligne:http://www.fcsh.unl.pt/iem/medievalista/MEDIEVALISTA2/PDF2/Lopo-PDF.pdf].

${ }^{59}$ Nous pensons notamment à la fin du royaume, avec les ambassades des chevaliers Vasco Martins, Alvaro Soares et João Lourenço da Covilhã.

${ }^{60}$ Envoyé à Avignon en 1326, il y avait séjourné pendant la fin du pontificat de Clément $\mathrm{V}$, la vacance et le début de celle de Jean XXII en tant que procureur du roi. Mário FARELO; Filipa ROLDÃO et André Evangelista MARQUES, Les clercs dans l'administration dionysienne (1279-1325), in Carreiras Eclesiásticas no Ocidente Cristão (séc. XII-XIV)/Ecclesiastical Careers in Western Christianity $\left(12^{\text {th }}-14^{\text {h }} \mathrm{C}\right.$.), Lisboa, 2007, p. 311.

${ }^{61}$ Martinho Afonso de Brito y était en 1332 pour représenter son frère João Afonso de Brito, évêque de Lisbonne, dans la question des dépouilles de l'évêque de Lamego avec la chambre Apostolique. Il fut l'un des ambassadeurs qui donna au pape la nouvelle de la victoire du Salado en 1341, séjour pendant lequel il a été élu évêque d'Evora. Voir le Tableau I et II.

${ }^{62}$ Voir le tableau I. 
de l'auditeur Aires Eanes dans le conflit sur la maîtrise portugaise de l'ordre de Saint Jacques ou bien se défendre eux-mêmes, à l'instar des accusations portées contre Pierre de Corbigny dont nous ne connaissons pas le contexte exact ${ }^{63}$.

Ces zones d'ombre semblent aussi caractériser les objectifs des ambassades au pape envoyées par le roi Pierre $\mathrm{I}^{\mathrm{er}}(1357-1367)$ pendant la décennie qu'il dirigea officiellement le destin du royaume. Même si les ambassades s'en suivirent au même rythme du règne précédent en termes d'une ambassade chaque vingt mois, les sources dont nous disposons pour les connaître relèvent surtout des suppliques, ce qui cache le plus souvent les objectifs principaux de la Monarchie dans leur déploiement. Nonobstant, dans la mesure où l'on peut voir, l'action de ce roi n'échappe pas à ce que l'on a vu précédemment concernant la recherche de nouvelles sources de revenu par la concession de décimes ecclésiastiques ou les demandes concernant les dispenses de mariages en faveur des membres de la famille royale (1357, $1360,1365)^{64}$. En ce sens, il est particulièrement digne de note les manœuvres diplomatiques du roi de façon à légitimer a posteriori son mariage avec Inès de Castro et la conséquente légitimation des enfants originaires de cette union ${ }^{65}$.

Pour ce faire, Pierre à fait confiance à des hommes versés en droit et qui connaissaient la Curie, puisqu'ils y avaient été au service de son père ${ }^{66}$. Cette manutention ne semble pas avoir été poursuivi pour les membres de la noblesse, dans la mesure où les ambassadeurs royaux appartenant à cet ordre furent avant tout des serviteurs très proches de Pierre dès la période de ses démêlées avec son père ${ }^{67}$. Curieusement, nous ne décelons plus une forte présence d'ecclésiastiques, peut-être un signe de la plus petite malléabilité du

${ }^{63} \mathrm{Le} R A 91$ registre aussi un «outro instrumento de fronta que Afonso Domingues, corregedor del rei fez ao arcebispo em razão da jurisdição de Braga» (fl. 313v), ce qui peut sous-entendre la nécessité d'officiers royaux rompus à la procédure pour défendre la position royale à la curie. Pour l'étude d'un procès très documenté et instruit par des juges pontificaux entre le royaume de Pologne et l'ordre Teutonique, voir Sylvain GOUGUENHEIM, Le procès pontifical de 1339 contre l'ordre Teutonique, «Revue historique», CCCX/3, p. 647 (juillet 2008), p. 567-603.

${ }^{64}$ Le seul changement majeur dans la typologie de sujets présentés alors par la Couronne au pape semble concerner la diminution de l'intervention royale dans la demande bénéficiale, comme d'ailleurs déjà constaté par Anne-Marie HAYEZ, Les demande de bénéfices présentées à Urbain $V$. Une approche géographico-politique, in Suppliques et Requêtes. Le gouvernement par la grâce en Occident (XII-XV siecle) (H. MILLET, ed.), Rome, 2003, p. 139.

${ }^{65}$ Sur cette question, voir MPV, vol. II, p. CCCLXVII-CCCLXXV.

${ }^{66} \mathrm{C}$ 'est le cas de maître Afonso das Leis. Quant à Geraldo Esteves, son office de surjuge et d'auditeur du roi l'oblige à être un spécialiste dans cette matière.

${ }^{67}$ Martim Vasques de Góis était frère de Gonçalo Vasques de Góis, sécrétaire de Pierre dès son dauphinat et ambassadeur d'Alphonse IV à Castille en 1336 pour négocier le mariage dudit dauphin avec Constance, fille de Juan Manuel (A. HoMEM, O Desembargo, p. 325-326; Ana Cláudia SILVEIRA, Acerca do Reguengo de Oeiras no Reinado de D. João I: o Património de Pero Vasques da Pedra Alcada, in VI Encontro de história local do Concelho de Oeiras. História, Espaço e Património Rural. Actas, Oeiras, 2005, p 68-69; Maria de Lurdes RosA, O Morgadio em Portugal, séculos XIV-XV. Modelos e práticas de comportamento linhagístico. Lisboa, 1995, p. 75-78) V Vasco Martins [Leitão] était fills du maître de l'ordre de Christ Martim Gonçalves Leitão et il fut alcaide de Portalegre en 1369 (Luís Filipe OLIVEIRA, A Coroa, Os Mestres e os Comendadores. As Ordens Militares de Avis e de Santiago (1330-1449), Faro, 2009, p. 471, 473). 
roi dans les liens maintenus avec le pouvoir spirituel au Portugal ${ }^{68}$ ou de la poursuite d'autres voies de représentation curiale.

L'instabilité politique et sociale qui caractérisa le règne de Ferdinand Ier a été l'une des causes de la majoration de l'activité diplomatique portugaise à Avignon. La question du mariage de la princesse Marie en $1375^{69}$, les concessions de décimes dans les deux années suivantes, les droit usurpés par le roi et la provision de l'archevêché de Braga, entre autres, firent porter la cadence d'ambassades à moins de 13 mois d'intervalle. Cette intensification des activités diplomatiques a été menée dans les premières années par des chevaliers qui, en réalité, étaient des conseillers du roi forts d'une longue expérience dans l'officialité royale ${ }^{70}$. Certainement à cause de la montée en importance des affaires ecclésiastiques à traiter à la curie, la dernière partie du règne a vu l'accroissement des ambassadeurs cléricaux qui devaient leurs parcours au roi et même d'un régulier, en l'occurrence fr. Martinho, abbé d'Alcobaça. Ces clercs - tels Martinho Gil, évêque d'Evora, lequel séjourna pendant quelques années à la curie ou même le castillan Martinho Eanes de Zamora, qui s'est fait récompenser par le roi avec l'octroi des évêchés de Silves, puis de Lisbonne- fonctionnaient maintenant de paire avec des nobles et des hauts fonctionnaires royaux dans le cadre de missions bicéphales ou tricéphales de façon à rendre compte, très certainement, de la diversité des affaires intéressante le roi ou ses agents.

En résumé, les rois portugais pendant la papauté d'Avignon n'ont pas innové dans le recrutement de ces ambassadeurs à la Curie. Choisis parmi ses plus proches serviteurs, le plus souvent membres de leurs conseils respectifs, parfois des étrangers, ils attestent pour la plupart une connaissance antérieur de la Curie ${ }^{71}$. La qualité des sujets y traités rend cette expérience nécessaire, puisque l'obtention de dispenses pour des mariages consanguins ou la demande de concession de décimes - les objectifs le plus représentés dans notre dénombrement- appellent à des négociations avec le pape et le consistoire. Chemin faisant, les nobles, les clercs et les lettrés qui y arrivent

\footnotetext{
${ }^{68}$ Sur les liens entre Pierre et le clergé de son règne, voir Cristina PimEnta, D. Pedro, Rio de Mouro, 2005, p. 124-131. Si la réaction violente du roi à l'adultère de l'évêque de Porto narré dans sa chronique ne se prouve pas (Fernão LOPES, Crónica de D. Pedro I (Damião PERES, org), Porto, 1965, p. 33-35), déjà l'implantation du beneplácito, du droit de regard sur la documentation papale ne fait pas de doute pendant son règne. Il est possible de trouver des développements sur ces questions dans Anísio SARAIVA, $O$ processo de inquirição do espólio de um prelado trecentista: D. Afonso Pires, bispo do Porto (1359-1372), «Lusitania Sacra», $2^{\mathrm{e}}$ série 13-14 (2001-2002), p. 203; António de Sousa ARAUJO, Beneplacito régio, in Dicionário de História Religiosa de Portugal (Carlos Moreira AZEVEDO, dir), vol. I, Rio de Mouro, 2000, p. 209-211.

${ }^{69}$ Guillaume Mollat, Grégoire XI et Marie Infante de Portugal, «Comptes rendus. Académie des Inscriptions et Belles-Lettres», 1 (1964) p. 52-53; António Domingues de Sousa CoSTA, Quem tratou do matrimónio da Infanta Dona Maria, Urbano V ou Gregorio XI?, «Itinerarium», 10 (1965), p. 488-515.

${ }^{70}$ Lourenco Goncalves et Afonso Domingues [de Beja] (II) (A. HoMEM, O Desembargo, p. 261-263 et 161-361). Ce dernier institua un majorat à Lisbonne dans la paroisse de SaintBarthélemy (ANTT, Arquivo do Hospital de São José, liv. 139, fl. 64-79; Chancelaria de D. Fernando, liv. 2, fl. $47 \mathrm{v}-48 \mathrm{v}$ ).

${ }^{71} \mathrm{Ce}$ trait d'un choix éminemment personnel du roi est souligné par Armando MARTINS, Diplomacia e gestos diplomáticos no reinado de D. Fernando [1367-1383], in Raizes medievais do Brasil moderno. Actas do Colóquio. 2 a 5 de Novembro 2007 (M. Garcez VENTURA, J. VARANDAS, coords.), Lisboa, 2008, p. 152.
} 
mirent à profit ses contacts pour quémander des grâces pour eux et leurs familles respectives ${ }^{72}$. Il faut penser que ces contacts se matérialisaient aussi dans le personnel que restait de forme continuée à la Curie.

\section{LES REPRÉSENTATIONS DE LA COURONNE: LES REPRÉSENTANTS SUR PLACE}

Il faut d'emblée reconnaître qu'il n'est pas aisé d'identifier les agents que la Couronne portugaise maintenait sur place pendant la période à l'étude, en grande partie parce l'étude de la communauté portugaise à Avignon au $\mathrm{XIV}^{\mathrm{e}}$ siècle reste à faire dans son entier ${ }^{73}$. Nonobstant, les quelques bribes d'informations disponibles suggèrent que la représentation de la Couronne sur place s'échelonnait autour de deux axes divergents dans le recrutement de leurs agents et de leurs lieux de insertion.

La représentation la plus efficace était sans doute celle basée sur les solidarités tissées par la Couronne avec des personnes hautement placées dans la machine bureaucratique et dignitaire de la curie pontificale et désignés sous le terme de promoteurs. Tout d'abord, le Portugal, comme les autres royaumes chrétiens, bénéficiait des moyens de capter la bienveillance d'un groupe comme celui des cardinaux, détenteur d'une capacité effective d'intervention et d'influence à la curie ${ }^{74}$. Étant donné que ceux-ci fonctionnait le plus souvent en termes de solidarités géographiques ${ }^{75}$, force est d'admettre que, sur ce point, la royauté portugaise restait défavorisée par l'absence d'un compatriote dans le Sacré-collège pendant la période avignonnaise. Cela a obligé le ralliement de la Couronne portugaise à des cardinaux étrangers et, de prime abord, à ceux issus de la Péninsule Ibérique. Dans l'impossibilité d'avancer des informations pour le cas Pedro Gomes Barroso (oncle),

\footnotetext{
${ }^{72}$ En effet, il était implicite qu'une ambassade royale donnait lieu à la demande des bénéfices en faveur des respectifs agents diplomatiques, de leurs familles, ainsi que des membres de la maisonnée du rol. Le fait que le groupe de quémandeurs liés aux activités de la chambre apostolique au Portugal ait devancé les ambassadeurs du roi en Curie en 1357 pour la demande des bénéfices vacants à la curie montre la compétition existante en matière bénéficiale et la constitution de deux groupes distincts: «antequam eorum possessiones occuparentur seu ambaxatores regis ad Curiam venerint, et hoc personis infrascriptis que Port[ugalie] sunt aut ibidem diu moram traxerunt et camere apostolice diu et feliciter servierunt». $M P V$, vol. I, p. 312 , n. 85

${ }^{73}$ La seule étude dont l'objectif peut s'en approximer est la publication d'un petit registre de João Esteves de Vila Verde, notaire apostolique. Anísio SARAIVA, "Clientuli et procuratores" na Avinhão de Clemente VI, segundo as notas de um notário português in Estudos em homenagem ao Professor Doutor José Marques (N. Alves, M. CunHA et F. RIBEIRO, eds.), vol. I, Porto, 2006, p. 227-244.

${ }^{74}$ Les justifications pour la bienveillance d'un ou de plusieurs cardinaux envers une Couronne pouvaient varier selon leurs intérêts bénéficiaux dans le royaume, des amitiés qu'ils pouvaiẹnt y entretenir ou même les engagements pris entre les parts. En effet, nous savons que certains cardinaux étaient à la solde d'une ou de plusieurs royautés comme démontré par K. PLÖGER, England and the Avignon Popes, p. 97.

${ }^{75}$ Ces solidarités étaient le plus visibles lors des conclaves servant à élire les papes. La relation entre la géographie et la constitution du Sacré collège est faite maintes fois dans la bibliographie spécialisée comme, par exemple, dans Bernard GUILLEMAIN, Les entourages des cardinaux à Avignon, in A l'ombre du pouvoir. Les entourages princiers au Moyen Age (A. MARCHANDISSE et J.-L. KUPPER, eds.), Genève, 2003, p. 7.
} 
cardinal-évêque de Sabina ${ }^{76}$, il est tout de même clair que Gil de Albornoz a maintenu une relation étroite avec le royaume lusitanien. Outre le très grand nombre de bénéfices ecclésiastiques portugais dont il aura l'usufruit ${ }^{77}$, sa livrée accueillera des personnes liées au roi comme Martinho Gil, chanoine de Porto et allumpno du monarque ${ }^{78}$, tandis que sa maison maintiendra des lusitaniens, à l'instar du futur évêque Lourenço Rodrigues/Martins de Barbudo $^{79}$. De plus, à une époque où de collège de cardinaux était dominé par les hommes issus des parties centrales et méridionales du royaume de France, il faut penser que la promotion des affaires portugais à la curie passait aussi par ces prélats qui bénéficiaient d'un accès au pape. En effet, la bonne marche de leurs politiques bénéficiaires - lesquelles s'étendaient alors à l'échelle de la Chrétienté- les rendait tout à fait attentifs aux demandes des rois où leurs bénéfices étaient localisés ${ }^{80}$. Celle-ci peut constituer une explication possible pour l'aide que le cardinal limousin Guillaume de la Jugie prêta en 1346 à l'avancement des négoces d'Alphonse IV et de la reine Béatrice ${ }^{81}$.

Plus bas dans l'hiérarchie, l'aide pouvait être toute aussi intéressée. Renaud de Maubernard fut l'un de ceux-là. Trésorier apostolique, c'est le propre Innocent VI qui justifiera son obtention du siège de Lisbonne avec l'intercession que le nouvel évêque pouvait exercer à la curie en faveur de la couronne lusitanienne ${ }^{82}$.

Ces solidarités étaient sans doute les plus spectaculaires et, vraisemblablement, les plus efficaces auxquelles la royauté pouvait aspirer en dehors

${ }^{76}$ Il fut le seul cardinal ibérique dès 1327 jusqu'en 1348. A partir de l'année suivante Gil de Albornoz fait son entrée dans le collège jusqu'en 1367. Pedro Gomes Barroso (neveu) fut le prochain castillan cardinal de 1371 à 1374 . Entre 1356 et 1362 l'Aragon eut «Son» cardinal dans la personne de Nicholaus Rossel et, après 1375, avec Pierre de Luna. Salvador Moxó, La promocion politica y social de los “letrados" en al'Corte de Alfonso XI, «Hispania», 1975, p. 8-9. José ZUNZUNEGUI ARAMBURU, La legación del cardenal Guillermo de la Jugie a Castilla y Aragón (1355-1358), "Anthologica Annua», 12 (1964), p. 133; Ramón ALOS, Ramón de, El Cardenal de Aragón, fray Nicolás Rossell, "Cuadernos de Trabalhos de la Escuela Española de Arqueología y Historia en Roma», 1 (1912), p. 15-65; R. OLIVAR BERTRAND, Alfonso IV el Benigno, p. 456-176.

${ }^{77}$ M. FARELO, Les clercs (sous presse).

${ }^{78} \mathrm{ASV}$, Camera Apostolica, Collectoriae 51, fl. 176v-177. Il fut aussi chanoine de Badajoz (..1351-1359..) et portionnaire de Lisbonne (..1348-1368), avant d'accéder à l'évêché d'Evora en 1368. ASV, Reg. Aven. 95, fl. 287; 114, fl. 182-183; ANTT, Convento de Sta. Maria de Chelas, m. 34, $\mathrm{n}^{\mathrm{O}}$ 680; MPV, vol. I, p. 375-376, doc. 213; Lettres secrètes et curiales d'Innocent VI (P. GasnaUlt, M-H. LAURENT et N. GotTeri, eds), Paris, 1959-1975, no 23155.

${ }^{79}$ Certainement proche du cardinal, il fut son chancelier avant que Lourenço Rodrigue retourne au Portugal après avoir obtenu l'évêché de Lisbonne. Sur ce personnage, voir M. FARELO, Les clercs (sous presse) et la bibliographie y mentionnée. Pierre Jugie affirme que les chanceliers des cardinaux étaient normalement des personnages de haut rang de la confiance de son maître. Pierre JUGIE, Les cardinaux légats et leurs archives au XIV siècle, in Offices, écrit et papauté (XIII ${ }^{e}-X V I I^{e}$ siècle) (A. JAMME e O. PONCET, orgs.), 2007, p. 78.

${ }^{80}$ Le fait que tant Guillaume de la Jugie, comme le déjà mentionné Gil de Albornoz, furent grandement bénéficiés au Portugal peut suggérẹr une liaison entre la tenue de bénéfices dans un royaume par un cardinal et son rôle d'agent curiale de la royauté de ce même royaume. Si cette hypothèse s'avère vraie, alors nous avons une série de possibles promoteurs qui passent pour des cardinaux castillans, aragonais et français. Le décompte de leurs bénéfices dans M. FARELO, Les clercs, (sous presse).

${ }^{81}$ MPV vol. I, p. 108-109, no 196; Mário FARELO, O Cabido da Sé de Lisboa e os seus cónegos (1277-1377). Mémoire de maîtrise, Faculdade de Letras de l'Universidade de Lisboa, 2003 , vol. II, p. 71.

${ }^{82}$ M. FARELO, Les clercs (sous presse). 
du propre pape. Or, on peut supposer qu'elles n'étaient opérationnelles qu'avec une quelconque rétribution, soit au niveau pécuniaire, soit au niveau juridictionnelle. Étant ainsi, il serait plus juste penser que la promotion plus «courante» des affaires du roi serait assurée par des prélats liés d'une manière ou d'autre au Portugal, mais qui ne bénéficiaient apparemment pas d'aucune insertion fonctionnelle à la Curie. De ce groupe nous retranchons bien entendu les prélats que s'y étaient refugié à la suite des démêlées avec la royauté et qui ont pu, à l'occasion, porter dommage à la réputation de ses membres ${ }^{83}$. Nonobstant, la plupart du temps l'action des prélats qui avaient une relation spécifique avec le royaume - parce qu'ils y occupaient un siège cathédral, par exemple- pouvait être positive comme le cas déjà mentionné de Renaud de Maubernard à la fin du règne d'Alphonse IV. Dans cette même ligne de pensée, le fils de ce dernier a pu bénéficier des services de l'évêque de Coimbra, Pedro Gomes Barroso. Passé à Avignon à la suite de l'animosité de Pierre, roi de Castille ${ }^{84}$, il y fit beaucoup de service au roi lusitanien en requérant et procurant en sa faveur, comme en témoigne le propre monarque en $1362^{85}$.

Ce dernier exemple permet de constater que la promotion des affaires royales à la Curie pourrait également avoir une tournure plus fonctionnelle et technique. Dans un milieu reconnu par sa complexité bureaucratique comme c'était le cas de la curie apostolique, la poursuite efficace des affaires appelait à l'intervention de spécialistes, dont les connaissances techniques et les solidarités pouvaient faire la différence entre le barrage aux portes du palais apostolique ou un entretien avec le pape ${ }^{86}$. Parmi ces techniciens de la

\footnotetext{
${ }^{83}$ Nous pensons notạmment à Fr. Estêvão, évệque de Lisbonne, qui a passé en cưrie à la suite des démêlées avẹc le roi Denis. Les intrigues qu'il lança à la curie ont rendu nécessaire la défense du roi par le biais d'une ambassade de Goncalo Pereira et Manuel Pessagno en 1320 (Fernando Félix LOPES, Das actividades políticas e religiosas de D. Fr. Estêvão, bispo que foi do Porto e de Lisboa, "Lusitania Sacra», VI (1962-1963), p. 69-70; Vítor Gomes TEIXEIRA, D. Fr. Estêvão, OFM: de Portugal a Avinhão, entre a fidelidade e a ingratidão, in Portogallo mediterrâneo (A). FONSECA et M. CADEDDU, eds.), Cagliari, 2001, p. 39-74). L'immixtion royale dans la juridiction temporelle de l'évêque dans la ville de Pơrto au XIV ${ }^{e}$ siècle dicta aussi l'exile de ses évêques, dont le cas le mieux connu demeure celui de Pedro Afonso, neveu de l'archevêque Gonçalo Pereira (Adelaide Millán COSTA, Comunidades urbanas de senhorio eclesiástico: a divergente experiencia das cidades do Porto e de Braga, in Estudos em homenagem ao Professor Doutor José Marques (N. ALVES, M. CUNHA et F. RIBEIRO, eds.), vol. I, Porto 2006, p. 77-85; Luís Miguel DUARTE, Um burgo medieval que muda de senhor: Episódios da vida do Porto Medievo, «Ler História», 5 (1985), p. 3-16; M. COELHO, O arcebispo, p. 402; José ANTUNES et alii, Conflitos políticos no reino de Portugal entre a Reconquista e a Expansão. Estado da questão "Revista de História das Ideias», vol. 6, 1 (1984), p. 121-126; António Domingues de Sousa COSTA, Litígios do século XIV sobre a Cidade do Porto, ventilados na Cúria Pontíficia, entre os prelados portuenses e o monarca, in Congresso Luso-espanhol de Estudo Medievais: XI Centenário da Presúria de Portucale por Vímara Peres, Porto, 1968, p. 141-143.

${ }^{84}$ Ana ARranz GuZMÁN, Pedro I ante los enfrentamientos entre concejos y prelados castellanos, «Anuario de Estudios Medievales», 30/1 (2000), p. 263.

${ }^{85}$ Chancelarias Portuguesas: D. Pedro I, p. 295 cité dans C. PIMENTA, D. Pedro, p. 191; Rafael SÁNCHEZ SESA, Obispos procedentes de Castilla y proyectos de reforma en la Sede de Coimbra (1358-1407), "Hispania Sacra», 51/104 (1999), p. 766.

${ }^{86}$ L'entrave à l'entrée au Sacré-Palais ou au palais du pape, par exemple, donnait lieu à la rédaction d'un document de facon à sauvegarder le procureur d'une éventuelle accusation de mauvaise représentation. Voir des exemples dans le registre de João Esteves de Vila Verdade, notaire apostolique portugais à Avignon entre 1346-1347 publiés dans A. SARAIVA, Clientuli, p 232-234, 239; ANTT, Mesa da Consciência e Ordens. Ordem de Santiago/Convento de Palmela, Antiga Colecção Especial, Documentos Particulares, m. 1, n. 27 (entree dans le palais du pape
} 
procédure, nous pensons notamment aux procureurs, que Pierre-Marie Berthe a récemment tracé les fonctions principales. Selon lui, ils pouvaient être désignés:

Ad impetrandum, s'exécutant notamment à la chancellerie dans le but de garantir l'octroi et la fabrication des bulles de concession de bénéfices. Ce sont leurs noms qui sont apposés au verso des bulles originales ${ }^{87}$.

Ad contradicendum, pour œuvrer dans l'Audience des Lettres contredites afin de défendre la pertinence de la grâce pontificale obtenue ou défier son octroi à autrui.

Ad agendum ou ad causas, afin de poursuivre les procès au SacréPalais ou chez les autres tribunaux apostoliques.

Ad promittendum, nommé pour faire l'engagement de son procuré auprès de la chambre Apostolique afin de payer à la Chambre apostoliques les communs et menus services.

Ad solvendum, pour payer les versements promis à la Chambre.

$A d$ visitandum, pour exécuter les visites aux tombeaux des apôtres.

Ad resignandum, afin de faire résigner le bénéfice majeur ou mineur de son client dans les mains d'un curial ${ }^{88}$.

Pour l'instant, il n'est guère possible d'établir l'existence d'un éventuel lien entre ces différentes formes de procuration et les cursa des agents portugais à la curie. Ainsi, en partant du principe que les solidarités géographiques jouaient aussi une grande influence dans cette question, nous pouvons néanmoins arriver à l'idée que les rois et les reines portugais comptaient davantage sur ses compatriotes agissant aux divers niveaux de la bureaucratie avignonnaise. Connaisseurs simultanément des affaires ibériques et des rouages curiales, ils se trouvaient dans une bonne place pour intervenir au niveau technique dans la représentation de la monarchie à la curie. Ainsi, on peut parier qu'Alphonse IV n'a pas manqué de retirer des dividendes de la proximité du pape et des connaissances techniques que ses compatriotes João Peres do Sem et Lourenço Rodrigues/Martins de Barbudo bénéficiaient en tant que auditeurs de la Rote $^{89}$; de João Rei, chanoine de Braga, scribe de la

par Estevão Esteves en 1350).

${ }^{87}$ Bernard BARBICHE, Homme d'affaires et pieux fondateur: Aubert de Guignicourt, procurador à la cour pontificale d'Avignon, in Finances, pouvoirs et mémoire. Mélanges offerts à Jean Favier (J. KERHERVÉ et A. RIGAUDIĖRE, éds.), Paris, 1999, p. 557; ID., Les procureurs des rois de France à la cour pontificale d'Avignon, in Aux origines de l'Etat moderne. Le fonctionnement administratif de la papauté d'Avignon, Actes de la table ronde organisée par EFR avec le concours du CNRS, du Conseil géneral de Vaucluse et de l'Université d'Avignon (Avignon, 23-24 janvier 1988), Rome, 1990, p. 84.

${ }^{88}$ Pierre-Marie BERTHE, Les procureurs à la cour pontificale d'Avignon au XIV siècle : les procureurs des prélats français sous Urbain V et Grégoire XI à la Chambre apostolique, Thèse de l'Ecole Nationale des Chartes, 2004

[Résumé en ligne : http://theses.enc.sorbonne.fr/document131.html]. Voir aussi Andreas SoHN, Les procureurs à la curie romaine. Pour une enquête internationale, "Mélanges de 1'Ecole Française de Rome. Moyen Age», 114/1 (2002), p. 371-389.

${ }^{89} \mathrm{Au}$ moins deux portugais ont été des auditeurs du Sacré-Palais apostolique pendant le règne d'Alphonse VI. Ce même Lourenço Rodrigues/Martins de Barbudo et João Peres do Sem. Leurs liaisons avec la Couronne sont évidentes, puisque le second est fils du chancelier Pedro do Sem, tandis que le premier a été clerc de la reine-mere Isabel (M. FARELO, Les clercs (sous presse); ID., A oligarquia, p. 685). 
pénitencerie apostolique entre au moins 1342 et $1347^{90}$ ou, plus tard, de la liaison de Vasco Domingues, dignitaire du chapitre de Lisbonne à la chancellerie pontificale ${ }^{91}$, dont l'activité en tant qu'exécuteurs de provisions apostoliques mérite une étude spécifique.

L'insertion de représentants de la Couronne dans la bureaucratie pontificale se complétait aussi avec les compatriotes qui suivirent des carrières dans la qualité d'avocats ${ }^{92}$ et de procureurs à la Curie. Ces procuratores Romana Curia se reconnaissent dans les procureurs attachés au service d'une ou de plusieurs institutions ecclésiastiques pendant une période plus au moins longue selon les cas attestés ${ }^{93}$ : tandis que ces procureurs spéciaux tels qu'Afonso Peres, chanoine de Silves et maitre João Domingues, clerc du diocèse de Viseu, furent repérés respectivement en $1359^{94}$ et $1339^{95}$, des hommes de la trempe d'un Domingos Peres da Lourinhã restèrent au service du diocèse de Lisbonne pendant plus de quinze ans ${ }^{96}$.

Maîtres de la procédure, ils étaient parmi les plus aptes à la représentation permanente du roi à la curie, une solution que la papauté jugeait bien plus efficace que les ambassades et les procureurs occasionnels établis par les souverainetés chrétiennes ${ }^{97}$. Nonobstant, la réalité de l'existence d'un procurator Regis Portugaliae en règle est difficilement perceptible dans la documentation. Cela se doit probablement à la prépondérance que les promoteurs et les procureurs occasionnels ont eue dans cette question ${ }^{98}$. Au

\footnotetext{
${ }^{90}$ Karl-Heinrich SCHÄFER, Die Ausgaben der apostolischen Kammer unter Benedikt XII., Klemens VI. und Innozenz VI. Paderborn, 1914, p. 201, 235, 330; Ludwig MOHLER, Die Einnahmen der apostolischen Kammer unter Klemens VI, Paderborn, 1931, p. 328, 360, 370, 410-411. Il fut exécuteur de provisions apostolique entre 1330 et 1334, ce qui peut laisser entendre une présence curiale dès cette époque.

${ }^{91}$ Vasco Domingues a été scribe de la Chambre apostolique entre au moins 1353 et 1361 , passant ensuite à l'office d'écrivain apostolique jusqu'en 1379. M. FARELO, $O$ Cabido, vol. II', p. 139-144.

${ }^{92}$ Le seul exemple trouvé concerne Martinho Eanes de Avignon. Étudiant à Avignon et procureur à la curie de D. Guilherme de La Garde, archevêque de Braga (1350-1352), il exerce son métier d'avocat à̀ la Curie avignonnaise, en demeurant à la livree de Gil de Albornoz, cardinal Hispano (1359-†c. 1361). Docteur en lois, il est mort à Montpellier, où très probablement il poursuivait une carrière d'enseignement dans l'université locale. ASV Camera Apostolica, Collectoriae 51, fl. 174; MPV, vol. I, p. 184, n. 364; p. 208, n. 425; p. 242, n. 527 ; p. 394, n. 247; p. 396, n. 250 ; p. 404, n. 263; p. 405 , n. 265.

${ }^{93}$ Pierre-Marie BERTHE, L'enregistrement à la curie pontificale au XIV siècle in Offices, écrit et papauté (XIII ${ }^{e}-X V I I^{e}$ siècle) (Armand JAMME et Olivier PONCET, eds.), Rome, 2007, p. 691.

${ }^{94}$ ASV, Camera Apostolica, Collectoriae 51, fl. 173.

${ }^{95}$ ANTT, Mosteiro de Alcobaça, $2^{\text {a }}$ inc., m. 21, n. 509; m. 27, n. 678.

${ }^{96} \mathrm{Il}$ est procurateur à la Curie du diocèse de Lisbonne au moins entre 1351 et 1366 et de Évora pendant les années, 1366 et 1368 . Sa permanence à Avignon ne serait pas sans relation avec l'épiscopat lisbonnais d'Étienne de la Garde (1344-1348), bien qu'il ne soit attesté dans la qualité de son familier et procureur qu'en 1352. ANTT, Mosteiro de Alcobaca, $2^{\mathrm{a}}$ inc., m. 91, n. 34 $M P V$, vol. I, p. 253-254, n. 544; M. FARELO, O Cabido, vol. II, p. 25-30.

${ }^{97} \mathrm{~A}$ cet effet, Clément VI affirme en 1349 que presque tous les princes catholiques avaient des promoteurs pour leurs affaires à la Curie (K. PLÖGER, England and the Avignon Popes, $\mathrm{p}$. 87) et l'on peut supposer que le cas portugais n'était pas une exception.

${ }^{98} \mathrm{Il}$ ne faut pas oublier que le propre envoi de documentation entre la Curie et le Portugal pouvait dépendre de la conjoncture, puisque il existe des références au transport de lettres pour le roi par des gens qui, manifestement, se déplacent à Avignon pour d'autres raisons ou, meme, par les envoyes apostoliques envoyés ponctuellement au Portugal. Des exemples précis de cette pratique sont mentionnés dans ASV, Reg. Aven. 91, fl. 290 (reception de quatre lettres de grâce par Domingos Palas en 1347); A. SARAIVA, «Clientuli, p. 235-236 (réception aussi en 1347 par
} 
fait, les parcours de clercs comme Rui Domingues ${ }^{99}$ ou Martinho Eanes II ${ }^{100}$ et, surtout, dudit Domingo Peres da Lourinhã ${ }^{701}$ peuvent laisser deviner que ce service du monarque était l'aboutissement d'une connaissance curiale obtenue au long des années de service dans la défense des intérêts des institutions et des individus lusitaniens ${ }^{102}$.

D'après les donnés ci-dessous avancées, il semble s'agencer deux profils de représentants de la Couronne portugais chez les papes avignonnais. D'une part, il faut citer les ambassatores et nuntii envoyés ponctuellement à la Curie. Recrutés parmi les plus proches serviteurs des monarques, ceux-ci semblent avoir respecté un certain équilibre entre les nominations d'ambassadeurs d'extraction noble et des ambassadeurs liés à l'ordo ecclésiastique. A partir du règne d'Alphonse IV, ce groupe a été renforcé par les lettrés, très souvent originaires des grands centres comme Lisbonne, Coimbra ou Santarém, à la suite des liens privilégies tissus entre ce roi et le monde urbain. Les marchands qui pouvaient devenir à l'occasion des représentants royaux de choix, s'en trouvent ici parfaitement exclus. De plus, tant les nobles que les lettrés et les clercs s'en déchargèrent des missions pour lesquelles il faudrait un mandat spécial. À par les naturelles questions gérées par la relation entre les droits civil et canonique, entre les juridictions royales et ecclésiastiques, les motifs les plus usuelles pour la constitution de ces ambassades tournaient autour de la quête de dispenses matrimoniales servant à rendre effectif les alliances dessinés avec leurs voisins ibériques et l'obtention des décimes ecclésiastiques destinées à épauler financièrement le roi dans leurs dépenses

João Martins de Arnóia de quatre lettres, l'une pour Alphonse IV, une autre pour Gonçalo Pereira et les deux autres destinés a l'abbé Estêvão Gonçalves et le monastère de S. Salvador de Fonte Arcada). La poursuite de procès à la curie par des institutions ecclésiastiques portugaises donne l'occasion à l'élaboration de documents qu'enregistrent le contrat des appelants avec une personne engagée pour son transport. Ces documents sont emboutis de dispositions de formulaire: ils indiquent l'appelant, ils registrent l'identité du caminheiro et sa condition attestée par un chapeau sur la tête, un bourdon à la main et une gourde attachée à la ceinture. Sont mentionnées ensuite les espèces monétaires que lui sont données et le fait qu'elles se destinent au voyage et à payer aux avocats et aux écrivains pour leur travail dans la poursuite de l'appellation. Ensuite, il s'engage à remettre, à l'arrivée, les nouvelles (recado) de démarches effectuées. Presque tous ces documents - élaborées après notre période - mentionnent leur intention à poursuivre sur une voie terrestre. Seulement dans le document daté de 1388 il est dit textuellement que le transporteur veut embarquer sur une nef germanique qui partirait à Magdebourg. ANTT, Colegiada Sta. Cruz do Castelo de Lisboa m. $7, n^{\circ} 303$ (1388, Jun. 17); Mosteiro de Ś. Vicente de Fora de Lisboa, $1^{\mathrm{a}}$ inc., m. $22, \mathrm{n}^{\mathrm{O}} 24$ (1404, Fev. 15); Colegiada de Sto. Estêvão de Alfama de Lisboa m. 13, n. 254 (1415, Mai. 29); Colegiada de Sta. Maria de Torres Vedras, m. $27, \mathrm{n}^{\circ}$ 1 (1428, Abr. 30); Mosteiro de Alcobaça, $2^{\mathrm{a}}$ inc., m. 53 n $\mathrm{n}^{\mathrm{O}} 20$ (1431, Out. 22); Mosteiro de S. Vicente de Fora de Lisboa, $2^{\mathrm{a}}$ inc., cx. 8, n 4 (1432, Mai. 1).

${ }^{99}$ Il a resté à la Curie dès au moins le mois de décembre 1315 à juin 1318 . Il a été nommément référé dans la qualité de procureur du roi en décembre 1317 dans la question maintenue entre le maître-géneral de l'ordre de Saint-Jacques et Lourenço Eanes, maître portugais de celle-ci. $M P V$, vol. II, p. LXI.

${ }^{100} \mathrm{Il}$ est désigné de procureur du roi Ferdinand $\mathrm{I}^{\mathrm{er}}$ dans des provisions apostoliques de bénéfices de novembre 1374 et de décembre 1375. (Grégoire XI (1370-1378). Lettres communes analysées d'après les registres dits d'Avignon et du Vatican (Anne-Marie HAYEZ et al.,eds.), annêes IV à VII, Rome, 1997-2008, p. 262, n. 31791; p. 736, n. 40651).

${ }^{101}$ Désigné dans la qualité de procureur de Ferdinand $\mathrm{I}^{\mathrm{er}}$, roi du Portugal, en novembre 1374. $M P V$, vol. III/1, p. 161-162, note 138 .

${ }^{102}$ Bernard Barbiche insiste sur le fait que la géographie semble être le seul trait distinctif du recrutement de ces procureurs. B. BARBICHE, Homme d'affaires, p. 558; P. BERTHE, Les procureurs.[résumé en ligne: http://theses.enc.sorbonne.fr/document13i.html] 
avec la défense ou offensive face à l'Infidèle. Ces séjours étaient rentabilisés par les demandes gracieuses pour eux et leurs familles.

La sociologie de l'autre profil de représentants de la Couronne, ceux qui restaient en place à la curie, demeure un sujet à caution. Un groupe formé vraisemblablement de curiaux étrangers et lusitaniens, leur force provenait de la connaissance de la machine judiciaire et administrative apostolique qui ne pouvait venir qu'à la suite d'une permanence effective. Réunis autour de solidarités géo-fonctionnelles, pourvus ou dépourvus d'une insertion effective à la curie, ils formaient un groupe de pression dont l'étendu et les ramifications sont encore à évaluer.

Date de réception de l'article: mai 2010.

Date d'acceptation et version finale: juillet 2010. 


\section{APPENDICE}

\begin{tabular}{|c|c|}
\hline & Abréviations \\
\hline Acta & $\begin{array}{l}\text { Acta Aragonensia; Quellen zur deutschen, italienischen, } \\
\text { französischen, spanischen, zur Kirchen- und } \\
\text { Kulturgeschichte aus der diplomatischen Korrespondenz } \\
\text { Jaymes II (Heinrich FINKE, ed.), Berlin-Leipzig, 1908- } \\
1922 .\end{array}$ \\
\hline Crónica & $\begin{array}{l}\text { Fernão LOPES, Crónica de D. João I (H.MORENO et A. } \\
\text { SÉRGIO, eds), vol. I, Lisboa, [s.d.]. }\end{array}$ \\
\hline Einnahmen & $\begin{array}{l}\text { Emil GÖLLER, Die Einnahmen der apostolischen Kammer } \\
\text { unter Johann XXII. Paderborn, } 1910 .\end{array}$ \\
\hline Embaixadores & $\begin{array}{l}\text { Saul António GOMES, Embaixadores de Portugal junto } \\
\text { da Santa Sé, in Dicionário de História Religiosa de } \\
\text { Portugal (Carlos Moreira AzEVEDo, dir), vol. II, Rio de } \\
\text { Mouro, 2000, p. 103-110. }\end{array}$ \\
\hline História & D. Rodrigo da CunHA, História Ecclesiastica da Igreia de \\
\hline Ecclesiastica & $\begin{array}{l}\text { Lisboa. Vida, e acçoens de sevs prelados \& varões } \\
\text { eminentes em santidade, que nella florecerão, Lisboa, } \\
1642 .\end{array}$ \\
\hline LCCVI (Étranger) & $\begin{array}{l}\text { Clément VI. Lettres closes, patentes et curiales intéressant } \\
\text { les pays autres que la France (E. DEPREZ et G. MOLLAT, } \\
\text { eds), Paris, 1960-1961. }\end{array}$ \\
\hline$L C G X I$ & $\begin{array}{l}\text { Grégoire XI (1370-1378). Lettres communes analysées } \\
\text { d'après les registres dits d'Avignon et du Vatican (Anne- } \\
\text { Marie HAYEZ et al., eds.), vol. I-III. Rome, 1992-1993 } \\
\text { (publiées); années IV à VII, Rome, 1997-2008 } \\
\text { (polycopiées). }\end{array}$ \\
\hline$L C J X X I I$ & $\begin{array}{l}\text { Lettres communes du pape Jean XXII (1316-1334). Lettres } \\
\text { communes analysées d'après les Registres dits d'Avignon } \\
\text { et du Vatican (G. MoLLAT, ed.), 1904-1947. }\end{array}$ \\
\hline$L C U V$ & $\begin{array}{l}\text { Urbain } V \text { (1362-1370). Lettres communes analysées } \\
\text { d'après les registres dits d'Avignon et du Vatican (M.-H. } \\
\text { LAURENT, ed.), Paris, 1954-1985. }\end{array}$ \\
\hline LSCBXII (Étranger) & $\begin{array}{l}\text { Benoît XII. Lettres closes patentes intéressant les pays } \\
\text { autres que la France) (J.M. VIDAL et G. MoLLAT, eds.), } \\
\text { Paris, 1913-1950. }\end{array}$ \\
\hline LSCGXI (Étranger) & $\begin{array}{l}\text { Lettres secrètes et curiales du pape Grégoire XI (1370- } \\
\text { 1378) intéressant les pays autres que la France publiées } \\
\text { ou analysées d'après les registres du Vatican (G. MoLLAT } \\
\text { ed.), Paris, 1962-1965. }\end{array}$ \\
\hline
\end{tabular}


LSCIVI

LSCJXXII

$M H$

$M P V$

A política

$Q E$

Quinta Parte

Relacions

Reg. Aven.

Reg. Vat.

Santa Sé

A sé

Sétima Parte

Sexta Parte

Thesaurus
Lettres secrètes et curiales d'Innocent VI (P. GASNAULT, M-H. LAurent et N. GotTeri, eds), Paris-Rome, 19592006.

Lettres secrètes et curiales de Jean XXII se rapportant à la France (A. Coulon et S. ClemENCET, eds.), Paris, 19001962.

Monumenta Henricina (A. DIAS, ed.), vol. I, Lisboa, 1960.

Monumenta Portugaliae Vaticana (A. CosTA, ed.), RomaBraga, 1968-1982. 4 vols.

Maria Margarida de Sá Nogueira LALANDA, A política externa de D. Afonso IV (1325-1357), «Arquipélago. Série História», XI (1989), p. 107-151.

$2^{\circ}$ Visconde de SANTARÉM, Quadro elementar das relações políticas e diplomáticas de Portugal com as diversas potências do mundo desde o princípio da monarquia portuguesa até aos nossos dias, Paris, 18421863. 17 tomes.

Fr. Francisco BRANDÃO, Quinta Parte da Monarquia Lusitana, $3^{\mathrm{e}}$ édition (António da Silva RÊGO, ed), Lisboa, 1976.

Josefina MUTGÉ I VIVES, Relacions entre Alfons el Benigne de Catalunya-Aragó i Alfons IV de Portugal, in XV Congreso de história de la Corona de Aragón. Actas. Relaciones de la Corona de Aragón con los Estados Cristianos Peninsulares (Siglos XIII-XV), vol. II, Zaragoza, Gobierno de Aragón-Departamento de Educación y Cultura, 1998, p. 477-492.

Archivio Segreto Vaticano, Registra Avenionensia.

Archivio Segreto Vaticano, Registra Vaticana.

António Domingues de Sousa CostA, Santa Sé, Portugal e a, in Dicionário de História de Portugal (J. SERRÃO, ed.), [s.1.], 1975, p. 455-461.

Anísio Miguel de Sousa BemHaja SARAIVA, A sé de Lamego na primeira metade do séc. XIV, (1296-1349), Leiria, 2003.

Fr. Rafael de Jesús, Sétima Parte da Monarquia Lusitana, Sétima Parte da Monarquia Lusitana, 1985.

Fr. Francisco BRANDÃo, Sexta Parte da Monarquia Lusitana, $3^{\mathrm{e}}$ édition (António da Silva RÊGO, ed), Lisboa, 1980 .

Edmund MARTÈNE et Ursin DURAND, Thesaurus novus anecdotorum, vol. II, Paris, 1717. 


\section{Tableau I - Les ambassades de la Couronne portugaise à la Curie apostolique (1309-1377)}

\begin{tabular}{|c|c|c|c|}
\hline Date & $\begin{array}{c}\text { Agents } \\
\text { diplomatiques }\end{array}$ & Mission & Sources \\
\hline $\begin{array}{l}2^{\mathrm{e}} \text { semestre } \\
1309 \quad- \\
\text { début } 1310\end{array}$ & & $\begin{array}{l}\text {-Provision de l'evêché de } \\
\text { Lisbonne }\end{array}$ & $\begin{array}{l}M P V \text {, vol. II, p. } \\
\text { XXXI, XXXV }\end{array}$ \\
\hline 1314 & $\begin{array}{l}\text { Vicente Eanes } \\
\text { [César] } \\
\text { João Lourenço [de } \\
\text { Monsaráz] }\end{array}$ & $\begin{array}{l}\text {-Biens de l'ordre du } \\
\text { Temple au Portugal }\end{array}$ & $\begin{array}{l}M P V \text {, vol. II, p. } \\
\text { XVI, XXXVIII; } \\
\text { Embaixadores, } \\
\text { p. } 108 \text {. }\end{array}$ \\
\hline $\begin{array}{l}2^{\mathrm{e}} \text { semestre } \\
1316\end{array}$ & $\begin{array}{l}\text { Vicente Eanes } \\
\text { [César] } \\
\text { João Lourenço [de } \\
\text { Monsaráz] }\end{array}$ & $\begin{array}{l}\text {-Engagement de l'amiral } \\
\text { Manuele Pessagno }\end{array}$ & $\begin{array}{l}\text { Sexta Parte, p. } \\
240,279 .\end{array}$ \\
\hline juillet 1317 & & $\begin{array}{l}\text {-Biens de l'ordre du } \\
\text { Temple au Portugal } \\
\text {-Dénoncer les attentats } \\
\text { contre le roi Denis } \\
\text {-Obtention de dispense de } \\
\text { résidence pour les clercs } \\
\text { du roi et la reine portugais }\end{array}$ & $\begin{array}{l}\text { MPV, vol. II, } \mathrm{p} . \\
\text { XL-XLI; } \\
L C J X X I I, \quad \mathrm{n}^{\mathrm{o}} \\
4321-4322 .\end{array}$ \\
\hline $\begin{array}{l}\text { fin } 1317- \\
\text { mars } 1318\end{array}$ & $\begin{array}{lr}\text { Manuele } & \text { Pessagno, } \\
\text { amiral } & \\
\text { Vicente } & \text { Eanes } \\
\text { [César]) } & \end{array}$ & $\begin{array}{l}\text {-Biens de l'ordre du } \\
\text { Temple au Portugal } \\
\text {-Existence du maître } \\
\text { portugais de l'ordre de } \\
\text { Saint-Jacques } \\
\text {-Donation au pape de } 4000 \\
\text { florins par le roi } \\
\text {-Remise des décimes } \\
\text { envoyées par les } \\
\text { collecteurs apostoliques } \\
\text {-Indulgence en faveur du } \\
\text { roi pour nommer un qui } \\
\text { l'absoudre en article de } \\
\text { mort }\end{array}$ & $\begin{array}{l}M P V \text {, vol. II, p. } \\
\text { LVI-LIX, LXI; } \\
Q E \text {, vol. IX, p. } \\
311-315 ; \quad M H, \\
\mathrm{n}^{\circ} 59, \mathrm{p} .90-110 ; \\
\text { Einnahmen, p. } \\
\text { 464; LCJXXII, } \\
\mathrm{n}^{\circ} 5279 ; \text { Quinta } \\
\text { Parte, fl. 139- } \\
\text { 139v; Sexta } \\
\text { Parte, p. 254; } \\
\text { Santa Sé, p. } \\
456 .\end{array}$ \\
\hline fin $1318-$ & João Lourenço [de & -Création de l'ordre du & $M P V$, vol. II, p. \\
\hline
\end{tabular}




\begin{tabular}{|c|c|c|c|}
\hline mars 1319 & $\begin{array}{l}\text { Monsaráz] } \\
\text { Pedro } \\
\text { chanoine } \\
\text { Coimbra }\end{array}$ & $\begin{array}{l}\text { Christ } \\
\text {-Indulgence en faveur du } \\
\text { roi pour nommer un } \\
\text { confesseur qui l'absoudre } \\
\text { en article de mort } \\
\text {-Concession de bénéfices } \\
\text { pour Pedro Peres }\end{array}$ & 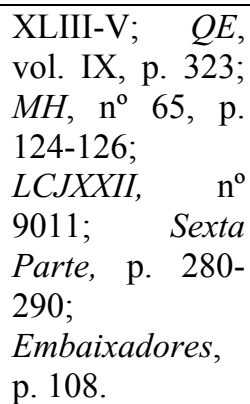 \\
\hline $\begin{array}{l}\text { janvier }- \\
\text { mars } 1320\end{array}$ & $\begin{array}{l}\text { Manuele Pessagno, } \\
\text { amiral } \\
\text { Gonçalo Pereira, } \\
\text { doyen de Porto }\end{array}$ & $\begin{array}{l}\text {-Concession des décimes } \\
\text { apostoliques pour la guerre } \\
\text { contre les maures } \\
\text {-Indulgentes pour la reine } \\
\text { Béatrice } \\
\text {-Défense du roi face aux } \\
\text { griefs de D. Fr. Estêvão, } \\
\text { évêque de Lisbonne }\end{array}$ & $\begin{array}{l}\text { QE, vol. IX, p. } \\
326 ; \quad L C J X X I I, \\
\mathrm{n}^{\mathrm{o}} 10780 ; \text { Sexta } \\
\text { Parte, p. 244, } \\
373 ; \\
\text { Embaixadores, } \\
\text { p. 108; Santa } \\
\text { Sé, p. } 456 .\end{array}$ \\
\hline 1322 & $\begin{array}{l}\text { Gomes } \quad \text { Eanes, } \\
\text { chevalier }\end{array}$ & $\begin{array}{l}\text {-Provision des églises de } \\
\text { Braga et Évora }\end{array}$ & $\begin{array}{l}\text { ASV, Reg. Vat. } \\
111 \text {, fl. } 71 ; \\
\text { Embaixadores, } \\
\text { p. 108; Santa } \\
\text { Sé, p. 456. }\end{array}$ \\
\hline 1324 & $\begin{array}{lr}\text { Gonçalo } & \text { Pereira, } \\
\text { doyen de Porto } \\
\text { Vasco } \\
\text { chanoine } \\
\text { Coimbra }\end{array}$ & $\begin{array}{l}\text {-Demande de dispenses } \\
\text { pour le mariage de Pierre, } \\
\text { petit-fils du roi Denis avec } \\
\text { Branca (non concédée) } \\
\text {-Réserves d'églises } \\
\text {-Demande de subside }\end{array}$ & $\begin{array}{l}\text { Reg. Aven. } 112 \text {, } \\
\text { fl. 209-210; } \\
\text { MPV, vol. II, p. } \\
\text { CXXX, CXLV; } \\
\text { Embaixadores, } \\
\text { p. 108; Santa } \\
\text { Sé, p. } 456 .\end{array}$ \\
\hline $\begin{array}{l}\text { février } \\
\text { août } 1325\end{array}$ & $\begin{array}{l}\text { Lopo Fernandes } \\
\text { Pacheco } \\
\text { João Afonso, doyen } \\
\text { d'Évora }\end{array}$ & $\begin{array}{l}\text {-Demande de dispenses } \\
\text { pour le mariage de Pierre, } \\
\text { petit-fils du roi Denis avec } \\
\text { Branca } \\
\text {-Demande de décimes } \\
\text { apostoliques } \\
\text {-Dispense de résidence } \\
\text { pour les clercs du roi et de } \\
\text { la reine } \\
\text {-Provision de l'évêché de } \\
\text { Coimbra } \\
\text {-Indulgences en faveur du } \\
\text { roi et de la reine pour }\end{array}$ & 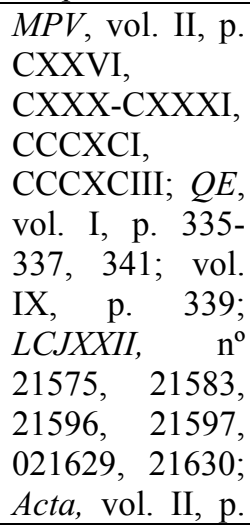 \\
\hline
\end{tabular}




\begin{tabular}{|c|c|c|c|}
\hline & & 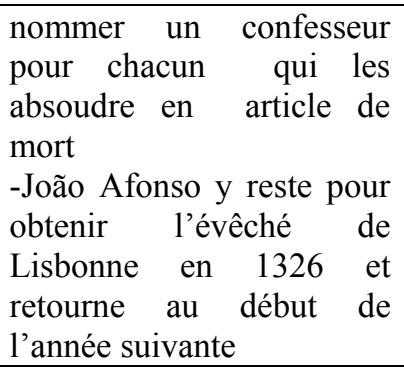 & $\begin{array}{l}\text { 595; A política, } \\
\text { p. } 135 ; \text { História } \\
\text { Ecclesiastica, fl. } \\
\text { 241v. }\end{array}$ \\
\hline mai 1326 & $\begin{array}{l}\text { Manuele } \\
\text { amiral }\end{array}$ & $\begin{array}{l}\text {-Demande des dispenses } \\
\text { pour Maria et Pierre, fils } \\
\text { du roi Alphonse IV } \\
\text {-Indulgences pour la reine } \\
\text { Béatrice } \\
\text {-Ces deux agents s'en vont } \\
\text { en Angleterre pour } \\
\text { négocier le mariage de } \\
\text { Maria avec le «prince } \\
\text { Noir» }\end{array}$ & $\begin{array}{l}Q E, \text { vol. IX, p. } \\
335-336 ; \text { vol. } \\
\text { XIV, p. 25-27; } \\
L C J X X I I, \quad \mathrm{n}^{\mathrm{o}} \\
25290-25294 ; \\
Q E, \text { vol. I, p. } \\
111,113,135- \\
136 .\end{array}$ \\
\hline $\begin{array}{l}\text { décembre } \\
1326\end{array}$ & $\begin{array}{l}\text { Lourenço Gomes de } \\
\text { Abreu }\end{array}$ & $\begin{array}{l}\text {-Il obtient des bénéfices } \\
\text { pour soi, étant clerc de la } \\
\text { reine-mère Isabel } \\
\text {-Bénéfices pour les clercs } \\
\text { de la reine }\end{array}$ & $\begin{array}{l}\text { LCJXXII, } \mathrm{n}^{\mathrm{o}} \\
27201,27328, \\
27569-27571 .\end{array}$ \\
\hline juillet 1327 & & $\begin{array}{l}\text {-Supplique sur le droit de } \\
\text { patronage royal de } \\
\text { certaines églises de Braga } \\
\text { (non concédée) }\end{array}$ & $\begin{array}{l}Q E \text {, vol. IX, p. } \\
\text { 341-342. }\end{array}$ \\
\hline $\begin{array}{l}\text { fin } 1329- \\
\text { début } 1330\end{array}$ & $\begin{array}{ll}\text { Lopo } & \text { Fernandes } \\
\text { Pacheco } & \end{array}$ & $\begin{array}{l}\text {-Demande de la dispense } \\
\text { pour le mariage de Maria, } \\
\text { fille du roi Alphonse IV } \\
\text { avec le roi de Castille (non } \\
\text { concédée) } \\
\text {-Concession de décimes } \\
\text { apostoliques } \\
\text { concédée) }\end{array}$ & $\begin{array}{l}M P V, \text { vol. I, p. } \\
\text { XCII-XCIII; } \\
Q E \text {, vol. I, p. } \\
\text { 152-153; Setima } \\
\text { Parte, p. 272- } \\
273 ; \text { A politica, } \\
\text { p. } \quad 135 ; \\
\text { Embaixadores, } \\
\text { p. 108; Santa } \\
\text { Sé, p. 456. }\end{array}$ \\
\hline juin 1330 & $\begin{array}{l}\text { Abbé de Saint-Jean } \\
\text { de Tarouca }\end{array}$ & -Inconnus & $\begin{array}{l}\text { Relacions, } \quad \mathrm{p} . \\
489 .\end{array}$ \\
\hline $\begin{array}{l}\text { fin } 1331- \\
\text { février } 1332\end{array}$ & $\begin{array}{l}\text { Pedro do Sem, } \\
\text { chanceler }\end{array}$ & $\begin{array}{l}\text {-Demande de la dispense } \\
\text { pour le mariage de Maria, } \\
\text { fille du roi Alphonse IV }\end{array}$ & $\begin{array}{l}\text { Reg. Aven. 91, } \\
\text { fl. } \quad 313 \mathrm{v} ; \\
\text { Einnahmen, p. }\end{array}$ \\
\hline
\end{tabular}




\begin{tabular}{|c|c|c|c|}
\hline & & $\begin{array}{l}\text { avec le roi de Castille } \\
\text {-Il paie une fraction des } \\
\text { services dus à la Curie par } \\
\text { Miguel Vivas, élu de } \\
\text { Viseu }\end{array}$ & $\begin{array}{l}\text { 254; A sé, p. } \\
864-871 ; \\
\text { Embaixadores, } \\
\text { p. 108; Santa } \\
\text { Sé, p. 456. }\end{array}$ \\
\hline $\begin{array}{l}\text { décembre } \\
1331-\text { juin } \\
1332\end{array}$ & $\begin{array}{l}\text { Gil Martins, } \\
\text { trésorier de Braga } \\
\text { Martim Afonso [de } \\
\text { Brito], chanoine de } \\
\text { Braga }\end{array}$ & $\begin{array}{l}\text {-Composition avec la } \\
\text { chambre Apostolique sur } \\
\text { les spolii de Rodrigo, } \\
\text { évêque de Lamego, dont } \\
\text { les deux sont les } \\
\text { exécuteurs testamentaires } \\
\text {-Gil Martins représente le } \\
\text { maître portugais de Saint } \\
\text { Jacques dans le conflit } \\
\text { avec la partie castillane de } \\
\text { l'ordre } \\
\text {-Gil Martins paie une } \\
\text { fraction des services dus à } \\
\text { la Curie par Miguel Vivas, } \\
\text { élu de Viseu } \\
\text {-Concession des décimes } \\
\text { apostoliques } \\
\text { concédées) } \\
\text {-Gil Martins est mort à la } \\
\text { curie avant le } 20 \text { novembre } \\
\text { 1333 }\end{array}$ & 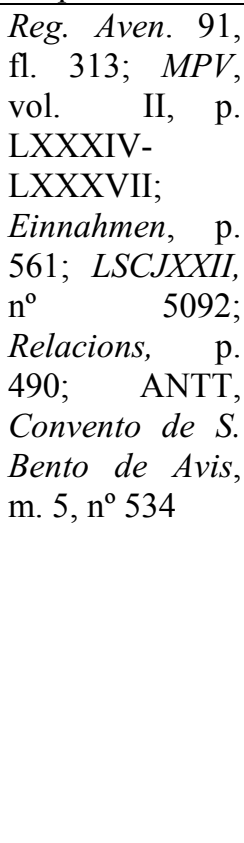 \\
\hline $\begin{array}{l}\text { avant juillet } \\
1334\end{array}$ & $\begin{array}{l}\text { Pedro do Sem, } \\
\text { chancelier } \\
\text { Aires } \\
\begin{array}{ll}\text { auditeur des } & \text { Causes } \\
\text { royales } & \end{array}\end{array}$ & $\begin{array}{l}\text {-Conflit sur le maître } \\
\text { portugais de l'ordre de } \\
\text { Saint Jacques }\end{array}$ & $\begin{array}{l}M P V \text {, vol. II, p. } \\
\text { LXXXIX; } \\
\text { Embaixadores, } \\
\text { p. 108; Santa } \\
\text { Sé, p. } 453 .\end{array}$ \\
\hline août 1335 & $\begin{array}{ll}\text { Pierre de } \\
\text { Corbigny/maître } \\
\text { Pedro das Leis }\end{array}$ & -Inconnus & $\begin{array}{l}\text { Relacions, } \quad \mathrm{p} . \\
489-490 .\end{array}$ \\
\hline $\begin{array}{l}\text { septembre } \\
1335\end{array}$ & $\begin{array}{lr}\text { Deux } & \text { chevaliers } \\
\text { [peut-être } & \text { Gonçalo } \\
\text { Vasques } & \text { de } \\
\text { Azevedo } & \mathrm{e} \\
\text { Lourenço } & \text { Gomes de } \\
\text { Abreu] } & \end{array}$ & & $\begin{array}{l}\text { Relacions, p. } \\
490 .\end{array}$ \\
\hline [1336-1338] & $\begin{array}{l}\text { Gonçalo Vasques } \\
\text { de Azevedo }\end{array}$ & $\begin{array}{lll}\text {-Sur la guerre entre } \\
\text { Portugal et Castille }\end{array}$ & $\begin{array}{l}\text { Reg. Aven. 91, } \\
\text { fl. } 313 .\end{array}$ \\
\hline
\end{tabular}




\begin{tabular}{|c|c|c|c|}
\hline & $\begin{array}{l}\text { Lourenço Gomes de } \\
\text { Abreu }\end{array}$ & & \\
\hline début 1339 & & $\begin{array}{l}\text {-Sur la guerre } \\
\text { Portugal et Castille }\end{array}$ & $\begin{array}{l}Q E, \text { vol. I, p. } \\
183 ; \quad \text { Setima } \\
\text { Parte, p. } 427 .\end{array}$ \\
\hline $\begin{array}{l}2^{\mathrm{e}} \text { semestre } \\
1340\end{array}$ & & $\begin{array}{l}\text {-Traiter du matrimoine du } \\
\text { dauphin Pierre }\end{array}$ & $\begin{array}{l}M P V \text {, vol. II, p. } \\
\text { CXXIV, } \\
\text { CXXIX. }\end{array}$ \\
\hline $\begin{array}{l}\text { fin } 1340- \\
\text { mars } 1341\end{array}$ & $\begin{array}{l}\text { Lopo Fernandes } \\
\text { Pacheco } \\
\text { Martinho, évêque } \\
\text { d'Évora } \\
\text { Lourenço Gomes de } \\
\text { Abreu }\end{array}$ & $\begin{array}{l}\text {-Concession des décimes } \\
\text { apostoliques et la } \\
\text { prédication de la Croisade } \\
\text {-Communication de la } \\
\text { victoire du Salado } \\
\text {-Lopo Fernandes obtient la } \\
\text { rose d'or ( } 3 \text { mars, date du } \\
4^{\mathrm{e}} \text { dimanche de Carême, } \\
\text { journée de la concession } \\
\text { de la rose d'or) }\end{array}$ & $\begin{array}{l}\begin{array}{l}L S C B X I I \\
\text { (Étranger), }\end{array} \\
\text { 3083; } \mathrm{n}^{\mathrm{o}} \\
\text { IX, p. } 349 .\end{array}$ \\
\hline 1344 & $\begin{array}{lr}\text { Gil } & \text { Martins, } \\
\text { chanoine } & \text { de } \\
\text { Lisbonne } & \end{array}$ & $\begin{array}{l}\text {-Envoyé de la reine à la } \\
\text { curie } \\
\text {-Probablement dans le } \\
\text { cadre de la demande de la } \\
\text { dispense pour le mariage } \\
\text { du dauphin Pedro de } \\
\text { Portugal avec Constança } \\
\text {-Il obtient des bénéfices } \\
\text { pour soi }\end{array}$ & $\begin{array}{l}\text { Reg. Aven. 75, } \\
\text { fl. 606-606v; } \\
M P V \text {, vol. I, p. } \\
\text { 28, n. } 51 .\end{array}$ \\
\hline $\begin{array}{l}\text { janvier } \quad- \\
\text { février } 1345\end{array}$ & $\begin{array}{l}\text { Maître João de } \\
\text { Lisboa (Maître João } \\
\text { das Leis) } \\
\text { Fernando } \\
\text { Gonçalves } \\
\text { Cogominho }\end{array}$ & $\begin{array}{l}\text {-Dispenses de mariages } \\
\text { pour Leonor, fille } \\
\text { d'Alphonse IV et pour } \\
\text { Maria, fille du dauphin } \\
\text { Pierre. } \\
\text {-Concession de décimes } \\
\text { apostoliques } \\
\text {-Obtention d'une dispense } \\
\text { pour accéder à l'épiscopat } \\
\text { en faveur d'un demi-frère } \\
\text { de maître João das Leis } \\
\text {-Obtention de } \\
\text { l'administration du majorat } \\
\text { et de la chapelle de maître } \\
\text { Pierre pour maître João das } \\
\text { Leis }\end{array}$ & $\begin{array}{l}\text { Reg. Aven. 79, } \\
\text { fl. 79, fl. 117- } \\
117 \mathrm{v}, 119, \\
136 \mathrm{v}-139 \mathrm{v} . \\
150 \mathrm{v}, 254 \mathrm{v} ; \\
M P V \text {, vol. I, p. } \\
\text { 49; QE, vol. IX, } \\
\text { p. 354; } \\
\text { Embaixadores, } \\
\text { p. 108; Santa } \\
\text { Sé, p. } 456 .\end{array}$ \\
\hline
\end{tabular}




\begin{tabular}{|c|c|c|c|}
\hline & & $\begin{array}{l}\text {-Concession de } \\
\text { rendements à l'université } \\
\text {-Bénéfices pour Fernando } \\
\text { Gonçalves Cogominho }\end{array}$ & \\
\hline juin 1347 & $\begin{array}{l}\text { Gonçalo, chevalier } \\
\text { et noble }\end{array}$ & $\begin{array}{l}\text {-Concession de décimes } \\
\text { apostoliques } \\
\text {-Dispense pour le mariage } \\
\text { de Leonor, fille } \\
\text { d'Alphonse IV avec le roi } \\
\text { d'Aragon } \\
\text {-Calunies lancées à la } \\
\text { Curie } \\
\text { l'ambassadeur contre } \\
\text {-Conflit du roi avec } \\
\text { l'évêque de Porto }\end{array}$ & $\begin{array}{l}L C C V I \\
\text { (Étranger), } \quad \mathrm{n}^{\mathrm{o}} \\
1410-1411 .\end{array}$ \\
\hline avril 1350 & $\begin{array}{l}\text { Geraldo Esteves de } \\
\text { Santarém }\end{array}$ & $\begin{array}{l}\text {-Geraldo Esteves demande } \\
\text { de bénéfices pour sa } \\
\text { famille }\end{array}$ & $\begin{array}{l}M P V, \text { vol. I, p. } \\
\text { 181-182, 283; } \\
\text { vol. II, p. CLV. }\end{array}$ \\
\hline $\begin{array}{l}\text { mars - avril } \\
1351\end{array}$ & $\begin{array}{l}\text { Pierre de } \\
\text { Corbigny/maître } \\
\text { Pedro das Leis }\end{array}$ & $\begin{array}{l}\text {-Calunies lancées au } \\
\text { Portugal contre maître } \\
\text { Pierre das Leis dont le } \\
\text { dauphin Pierre ne doit pas } \\
\text { croire }\end{array}$ & $\begin{array}{l}L C C V I \\
\text { (Étranger), } \mathrm{n}^{\mathrm{o}} \\
2413 ; \mathrm{MPV}, \\
\text { vol. I, p. 209- } \\
212 \text {; vol. II, p. } \\
\text { XLVI. }\end{array}$ \\
\hline $\begin{array}{l}\text { novembre } \\
1351\end{array}$ & $\begin{array}{l}\text { L'ambassadeur était } \\
\text { consanguin de } \\
\text { Gonçalo Martins, } \\
\text { recteur de l'église } \\
\text { de Sainte-Marie de } \\
\text { Covas }\end{array}$ & $\begin{array}{l}\text {-Calunies lancées au } \\
\text { Portugal contre maître } \\
\text { Pierre das Leis dont le } \\
\text { dauphin Pierre ne doit pas } \\
\text { croire }\end{array}$ & $\begin{array}{l}\text { Reg. Aven. 117, } \\
\text { fl. 106v-107; } \\
\text { LCCVI } \\
\text { (Étranger), } \mathrm{n}^{\circ} \\
\text { 2523; MPV, vol. } \\
\text { I, p. 236-237. }\end{array}$ \\
\hline $\begin{array}{l}\text { février } \quad- \\
\text { mars } 1352\end{array}$ & $\begin{array}{l}\text { João } \\
\text { professeur de droit } \\
\text { civil } \\
\text { Gonçalo Mendes de } \\
\text { Vasconcelos }\end{array}$ & $\begin{array}{l}\text {-Indulgences pour João } \\
\text { Afonso, pour des membres } \\
\text { de sa famille et amis } \\
\text {-João Afonso demeure à la } \\
\text { curie tout au moins jusqu'à } \\
\text { sa nomination à l'évêché } \\
\text { d'Évora le } 3 \text { octobre de } \\
\text { cette année } \\
\text {-Indulgences pour Gonçalo } \\
\text { Mendes de Vasconcelos et } \\
\text { sa femme Leonor } \\
\text { Rodrigues, inconnue des }\end{array}$ & $\begin{array}{l}\text { Reg. Aven. 113, } \\
\text { fl. 532, 533; } \\
\text { MPV, vol. I, p. } \\
233-234, \quad 247, \\
268 ; \text { vol. II, p. } \\
\text { CLV; } \\
\text { Embaixadores, } \\
\text { p. } 108 .\end{array}$ \\
\hline
\end{tabular}




\begin{tabular}{|c|c|c|c|}
\hline & & nobiliaires & \\
\hline $\begin{array}{l}\text { novembre } \\
1353\end{array}$ & $\begin{array}{l}\text { Pierre de } \\
\text { Corbigny/maître } \\
\text { Pedro das Leis } \\
\text { Rodrigo Gomes }\end{array}$ & $\begin{array}{l}\text {-Mariage du dauphin } \\
\text { Pierre et d'une des filles du } \\
\text { roi de France } \\
\text {-Demande de bénéfices } \\
\text { pour les clients de Pierre } \\
\text { de Corbigny }\end{array}$ & $\begin{array}{l}M P V \text {, vol. I, p. } \\
\text { 283-284; vol. II, } \\
\text { p. XLVI, CLIII- } \\
\text { V, VII; LSCIVI, } \\
\mathrm{n}^{\mathrm{o}} 614 ; \\
\text { Embaixadores, } \\
\text { p. 108; Santa } \\
\text { Sé, p. 456. }\end{array}$ \\
\hline début 1355 & & $\begin{array}{l}\text {-Concession des décimes } \\
\text { apostoliques }\end{array}$ & $\begin{array}{l}\text { Reg. Aven. } 130 \text {, } \\
\text { fl. } 451 ; Q E \text {, vol. } \\
\text { IX, p. } 355 \text {; } \\
\text { ANTT,. Bulas, } \\
\text { m. } 3 \text { m. } 2 .\end{array}$ \\
\hline juin 1355 & $\begin{array}{l}\text { Afonso Raimundo, } \\
\text { clerc, licencié en } \\
\text { lois }\end{array}$ & $\begin{array}{l}\text {-Indulgence pour lui et sa } \\
\text { femme, Maria Rodrigues, } \\
\text { citoyens de Coimbra } \\
\text {-Les thèmes principaux de } \\
\text { la mission demeurent } \\
\text { inconnus }\end{array}$ & $\begin{array}{l}\text { Reg. Aven. 131, } \\
\text { fl. 320; MPV, } \\
\text { vol. I, p. 300, } \\
\text { 302; vol. II, p. } \\
\text { CLIV; } \\
\text { Embaixadores, } \\
\text { p. } 108 .\end{array}$ \\
\hline $\begin{array}{l}\text { octobre } \\
1356\end{array}$ & $\begin{array}{l}\text { Vasco } \\
\text { chevalier }\end{array}$ & $\begin{array}{l}\text {-Provision de l'évêché de } \\
\text { Lisbonne }\end{array}$ & $\begin{array}{l}\text { LSCIVI, } \quad \mathrm{n}^{\circ} \\
2422 .\end{array}$ \\
\hline $\begin{array}{l}\text { mai - juillet } \\
1357\end{array}$ & $\begin{array}{l}\text { Álvaro Soares, } \\
\text { chevalier } \\
\text { João Lourenço da } \\
\text { Covilhã, chevalier }\end{array}$ & $\begin{array}{l}\text {-Des pétitions royales que } \\
\text { le pape et les cardinaux } \\
\text { n'ont pas pu satisfaire } \\
\text {-Demande de bénéfices } \\
\text { pour Alphonse IV et pour } \\
\text { la reine } \\
\text {-Demande de bénéfices au } \\
\text { nom de Álvaro Soares } \\
\text { pour lui, sa femme, Branca } \\
\text { Esteves du diocèse de Tui, } \\
\text { pour des membres de sa } \\
\text { famille et sa maisonnée } \\
\text {-Demande de bénéfices au } \\
\text { nom de João Lourenço, de } \\
\text { sa femme Aldonça Eanes } \\
\text { du diocèse de Guarda, de } \\
\text { leur fils Gomes Lourenço } \\
\text { et leur maisonnée } \\
\text {-L'annonce de la mort }\end{array}$ & $\begin{array}{l}\text { MPV, vol. I, p. } \\
311-312, \quad 315- \\
316, \quad 319-322 ; \\
\text { vol. II, p. CLIV; } \\
\text { LSCIVI, } \mathrm{n}^{\circ} \\
1628, \quad 2838, \\
2887 ; \text { QE, vol. } \\
\text { IX, p. 359; } \\
\text { Embaixadores, } \\
\text { p. } 108 .\end{array}$ \\
\hline
\end{tabular}




\begin{tabular}{|c|c|c|c|}
\hline & & $\begin{array}{l}\text { d'Alphonse XI force } \\
\text { Innocent VI à les faire } \\
\text { renvoyer au Portugal et à } \\
\text { avertir le nouveau roi de la } \\
\text { réponse qui leur fut donnée }\end{array}$ & \\
\hline juin 1358 & $\begin{array}{l}\text { Martim Vasques de } \\
\text { Góis }\end{array}$ & $\begin{array}{l}\text {-Demande de bénéfices } \\
\text { pour sa famille et sa } \\
\text { maisonnée } \\
\text {-Demande de bénéfices } \\
\text { pour la reine Beatriz }\end{array}$ & $\begin{array}{l}\text { MPV, vol. I, p. } \\
\text { 339-342; 342; } \\
\text { vol. II, p. CLIV, } \\
\text { Embaixadores, } \\
\text { p. 108; Santa } \\
\text { Sé, p. 456. }\end{array}$ \\
\hline juillet 1361 & $\begin{array}{l}\text { Geraldo Esteves } \\
\text { maître Afonso das } \\
\text { Leis }\end{array}$ & $\begin{array}{l}\text {-Dispense } \\
\text { consanguinité } \\
\text { légitimer le mariage de } \\
\text { Pierre et d'Inès (non- } \\
\text { concédée) } \\
\text {-Légitimation des enfants } \\
\text { de Pierre et d'Inès } \\
\text { (accordée). } \\
\text {-Dispenses et indulgences } \\
\text { pour toute la progéniture } \\
\text { du roi Pierre } \\
\text {-Demande de bénéfices au } \\
\text { nom du roi } \\
\text {-Concession de décimes } \\
\text { apostoliques } \\
\text { concédée) } \\
\text {-Provision d'évêchés }\end{array}$ & $\begin{array}{l}\text { Reg. Aven. 145, } \\
\text { fl. 340, 469, } \\
\text { 506, 508; 146, } \\
\text { fl. 598; MPV, } \\
\text { vol. I, 387-390; } \\
\text { vol. II, p. } \\
\text { CCCLXXIII; } \\
\text { Thesaurus, coll. } \\
\text { 1030-1031; } \\
\text { Crónica, vol. I, } \\
\text { p. 416-419; } \\
\text { ANTT, Arquivo } \\
\text { do Hospital de } \\
\text { S. José, liv. 8, } \\
\text { fl. 120-125v; } \\
\text { liv. 12, fl. 338- } \\
\text { 345v; liv. 1189, } \\
\text { fl. 42-48v ; liv. } \\
\text { 1191, fl. 167- } \\
\text { 173v. }\end{array}$ \\
\hline juin 1363 & $\begin{array}{l}\text { Vasco Martins } \\
\text { [Leitão], noble et } \\
\text { chevalier } \\
\text { Geraldo Esteves }\end{array}$ & $\begin{array}{l}\text {-Demande d'indulgence en } \\
\text { article de mort pour Vasco } \\
\text { Martins et son épouse } \\
\text { Senhorinha Vasques et } \\
\text { pour des officiers royaux } \\
\text {-Demande de bénéfices } \\
\text { pour des familiers de } \\
\text { Vasco Martins } \\
\text {-Demande de bénéfices } \\
\text { pour des membres de la } \\
\text { famille de Geraldo Esteves }\end{array}$ & $\begin{array}{l}M P V \text {, vol. I, p. } \\
439-440, \\
445 ; \\
\text { Embaixadores, } \\
\text { p. 108; Santa } \\
\text { Sé, p. } 453 .\end{array}$ \\
\hline septembre & Geraldo Esteves & -Demande de bénéfices & $M P V$, vol. I, p. \\
\hline
\end{tabular}




\begin{tabular}{|c|c|c|c|}
\hline $\begin{array}{lr}1365 & - \\
\text { janvier } & 1366\end{array}$ & & $\begin{array}{l}\text { pour des membres de sa } \\
\text { famille e de ses relations } \\
\text {-sur le mariage de Pierre, } \\
\text { roi de Castille avec une des } \\
\text { filles de Pierre, roi du } \\
\text { Portugal }\end{array}$ & 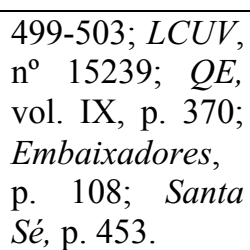 \\
\hline juillet 1366 & Geraldo Esteves & $\begin{array}{l}\text {-Demande de bénéfices } \\
\text { pour lui et des membres de } \\
\text { sa famille }\end{array}$ & $\begin{array}{l}M P V \text {, vol. I, p. } \\
511-512\end{array}$ \\
\hline $\begin{array}{l}\text { novembre } \\
1367\end{array}$ & & -Prêter révérence au pape & $\begin{array}{l}\text { Reg Vat. 249, fl. } \\
\text { 9-9v. }\end{array}$ \\
\hline août 1370 & $\begin{array}{l}\text { Lourenço } \\
\text { Gonçalves, } \\
\text { chevalier } \\
\text { Afonso Domingues, } \\
\text { chevalier }\end{array}$ & & $\begin{array}{l}\text { Reg Vat. 250, fl. } \\
136 .\end{array}$ \\
\hline $\begin{array}{l}\text { septembre } \\
1372\end{array}$ & $\begin{array}{l}\text { Gonçalo Peres, } \\
\text { noble }\end{array}$ & $\begin{array}{l}\text {-Provision de l'archevêché } \\
\text { de Braga }\end{array}$ & $\begin{array}{l}L S C G X I \\
\text { (Étranger), } \mathrm{n}^{\circ} \\
990 .\end{array}$ \\
\hline $\begin{array}{l}\text { janvier } \quad- \\
\text { février } 1374\end{array}$ & $\begin{array}{l}\text { Martinho, évêque } \\
\text { d'Évora }\end{array}$ & $\begin{array}{l}\text { - Restitution des droits } \\
\text { appartenant à des } \\
\text { personnes ecclésiastiques } \\
\text { portugaise et usurpés par le } \\
\text { roi } \\
\text {-Demande des bénéfices } \\
\text { pour les clercs du roi et de } \\
\text { la reine }\end{array}$ & $\begin{array}{l}\text { LSCGXI } \\
\text { (Étranger), } \quad \mathrm{n}^{\mathrm{o}} \\
2466 ; \quad L C G X I, \\
\mathrm{n}^{\circ} \text { 31995-31997, } \\
\text { 31999-32004. }\end{array}$ \\
\hline $\begin{array}{l}\text { décembre } \\
1374\end{array}$ & $\begin{array}{l}\text { Martinho, évêque } \\
\text { d'Évora } \\
\text { Vasco Gonçalves, } \\
\text { chanoine de } \\
\text { Lisbonne }\end{array}$ & $\begin{array}{l}\text {-Demande de bénéfices } \\
\text { pour Vasco Gonçalves }\end{array}$ & $\begin{array}{l}\text { LCGXI, } \quad \mathrm{n}^{\mathrm{o}} \\
32414, \quad 34705 ; \\
\text { LSCGXI } \\
\text { (Étranger), } \quad \mathrm{n}^{\mathrm{o}} \\
2466 .\end{array}$ \\
\hline $\begin{array}{l}\text { mars - mai } \\
1376\end{array}$ & $\begin{array}{l}\text { Martinho, évêque } \\
\text { de Silves } \\
\text { Martinho, abbé } \\
\text { d'Alcobaça } \\
\text { Álvaro Gonçalves } \\
\text { de Moura }\end{array}$ & $\begin{array}{l}\text {-Concession des décimes } \\
\text { apostoliques } \\
\text {-Demande de bénéfices } \\
\text { pour Martinho, évêque } \\
\text { d'Évora }\end{array}$ & $\begin{array}{l}L C G X I, \quad \mathrm{n}^{\circ} \\
44563, \quad 44689- \\
44690 ; Q E, \text { vol. } \\
\text { IX, p. 377-378. }\end{array}$ \\
\hline $\begin{array}{l}\text { octobre } \quad- \\
\text { novembre } \\
1377\end{array}$ & \begin{tabular}{lr}
\multicolumn{2}{l}{ Pedro Cavaleiro, } \\
archidiacre \\
Lisbonne \\
Lourenço \\
Fogaça, chancelier
\end{tabular} & $\begin{array}{l}\text {-Concession des décimes } \\
\text { apostoliques } \\
\text {-Demande des bénéfices } \\
\text { pour Pedro Cavaleiro } \\
\text {-Demande d'indulgences }\end{array}$ & $\begin{array}{l}L C G X I, \quad \mathrm{n}^{\circ} \\
44563, \quad 47974, \\
49122-49124, \\
49129, \quad 49229, \\
49148 ;\end{array}$ \\
\hline
\end{tabular}




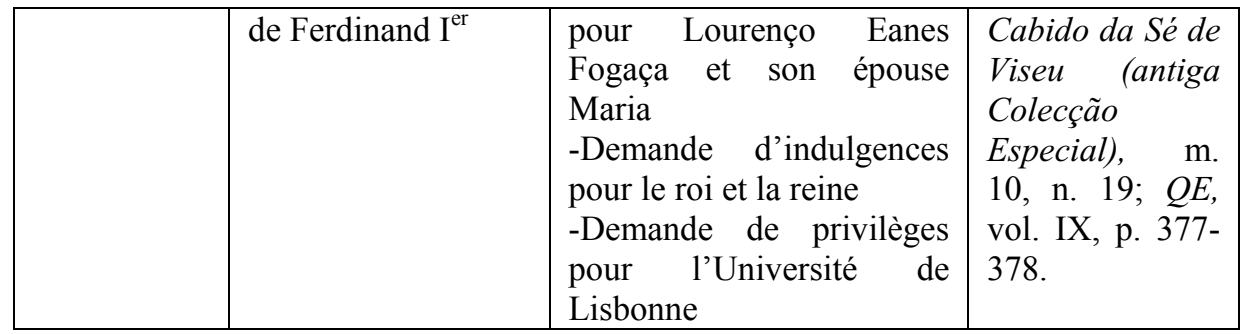

\section{Tableau II - Les ambassadeurs de la Couronne portugaise à la Curie apostolique (1309-1377)}

1)Règne de Denis $I^{\text {er }}(1309-1325)$

\begin{tabular}{|c|c|c|c|c|}
\hline $\begin{array}{c}\text { Agents } \\
\text { diplomatiques }\end{array}$ & $\begin{array}{l}\text { Ambassades } \\
\text { à la Curie }\end{array}$ & $\begin{array}{c}\text { Autres } \\
\text { ambassades }\end{array}$ & Statut & $\begin{array}{l}\text { Charges, } \\
\text { offices, } \\
\text { dignités }\end{array}$ \\
\hline $\begin{array}{l}\text { Vicente Eanes } \\
\text { [César] }\end{array}$ & $\begin{array}{l}1314 \\
1316 \\
1317-1318 \\
1318-1319\end{array}$ & & Noble & $\begin{array}{l}\text { Surjuge du } \\
\text { roi }\end{array}$ \\
\hline $\begin{array}{l}\text { João Lourenço } \\
\text { [de Monsaraz] }\end{array}$ & $\begin{array}{l}1314 \\
1316\end{array}$ & & Noble & \\
\hline $\begin{array}{l}\text { Manuele } \\
\text { Pessagno, } \\
\text { amiral }\end{array}$ & $\begin{array}{l}1317-1318 \\
1320\end{array}$ & & Noble & $\begin{array}{ll}\text { Amiral de } \\
\text { Portugal }\end{array}$ \\
\hline Pedro Peres & $1318-1319$ & & Clerc & $\begin{array}{l}\text { Chanoine de } \\
\text { Coimbra, } \\
\text { doyen de } \\
\text { Porto }\end{array}$ \\
\hline $\begin{array}{l}\text { Gonçalo } \\
\text { Pereira, doyen } \\
\text { de Porto }\end{array}$ & $\begin{array}{l}1320 \\
1324\end{array}$ & & Clerc & $\begin{array}{l}\text { Doyen de } \\
\text { Porto; } \\
\text { évêque de } \\
\text { Lisbonne; } \\
\text { archevêque } \\
\text { de Braga }\end{array}$ \\
\hline Vasco Martins & 1324 & & Clerc & $\begin{array}{l}\text { Chanoine de } \\
\text { Lisbonne, } \\
\text { évêque de }\end{array}$ \\
\hline
\end{tabular}




\begin{tabular}{|l|l|l|l|l|}
\hline & & & $\begin{array}{l}\text { Porto; } \\
\text { évêque de } \\
\text { Lisbonne }\end{array}$ \\
\hline
\end{tabular}

2)Règne d'Alphonse IV (1325-1357)

\begin{tabular}{|c|c|c|c|c|}
\hline $\begin{array}{c}\text { Agents } \\
\text { diplomatiques }\end{array}$ & $\begin{array}{l}\text { Ambassades à } \\
\text { la Curie }\end{array}$ & $\begin{array}{c}\text { Autres } \\
\text { ambassades }\end{array}$ & Statut & $\begin{array}{l}\text { Charges, } \\
\text { offices, } \\
\text { dignités } \\
\end{array}$ \\
\hline $\begin{array}{l}\text { Lopo Fernandes } \\
\text { Pacheco }\end{array}$ & $\begin{array}{l}1325 \\
1329-1330 \\
1340-1341\end{array}$ & $\begin{array}{l}\text { Aragon (1325, } \\
1329) \\
\text { Castille (1338) }\end{array}$ & Noble & $\begin{array}{l}\text { Conseiller } \\
\text { du roi; } \\
\text { meirinho- } \\
\text { mor du } \\
\text { dauphin } \\
\text { Pierre; } \\
\text { chancelier } \\
\text { de la reine } \\
\text { Beatriz }\end{array}$ \\
\hline $\begin{array}{l}\text { João Afonso de } \\
\text { Brito }\end{array}$ & 1325 & & Clerc & $\begin{array}{l}\text { Doyen } \\
\text { d'Évora; } \\
\text { évêque de } \\
\text { Lisbonne; } \\
\text { conseiller du } \\
\text { roi }\end{array}$ \\
\hline $\begin{array}{l}\text { Manuele } \\
\text { Pessagno }\end{array}$ & 1326 & $\begin{array}{l}\text { Angleterre } \\
(1326)\end{array}$ & Noble & $\begin{array}{ll}\text { Amiral de } \\
\text { Portugal }\end{array}$ \\
\hline $\begin{array}{l}\text { Maître Rodrigo } \\
\text { Domingues }\end{array}$ & 1326 & $\begin{array}{l}\text { Angleterre } \\
(1326)\end{array}$ & Clerc & $\begin{array}{l}\text { Chanoine de } \\
\text { Lisbonne }\end{array}$ \\
\hline $\begin{array}{l}\text { Lourenço } \\
\text { Gomes de } \\
\text { Abreu }\end{array}$ & $\begin{array}{l}1326 \\
{[1336-1338]} \\
1341 \\
\end{array}$ & $\begin{array}{l}\text { Aragon (1327) } \\
\text { Castille (1338) }\end{array}$ & Noble & \\
\hline $\begin{array}{l}\text { Abbé } \\
\text { Tarouca }\end{array}$ & 1330 & & $\begin{array}{l}\text { Clerc } \\
\text { régulier }\end{array}$ & $\begin{array}{l}\text { Abbé de } \\
\text { Tarouca }\end{array}$ \\
\hline Pedro do Sem & $\begin{array}{l}1331-1332 \\
1334\end{array}$ & & Chevalier & $\begin{array}{l}\text { Chancelier } \\
\text { du roi }\end{array}$ \\
\hline Gil Martins & 1332 & & Clerc & $\begin{array}{l}\text { Trésorier de } \\
\text { Braga }\end{array}$ \\
\hline $\begin{array}{l}\text { Martim Afonso } \\
\text { de Brito }\end{array}$ & $\begin{array}{l}1332 \\
1340-1341\end{array}$ & & Clerc & $\begin{array}{l}\text { Chanoine de } \\
\text { Braga; } \\
\text { évêque } \\
\text { d'Évora }\end{array}$ \\
\hline
\end{tabular}




\begin{tabular}{|c|c|c|c|c|}
\hline Aires Eanes & 1334 & & Lettré & $\begin{array}{l}\text { Auditeur des } \\
\text { Causes } \\
\text { royales }\end{array}$ \\
\hline $\begin{array}{l}\text { Pierre de } \\
\text { Corbigny/ } \\
\text { maître Pedro } \\
\text { das Leis }\end{array}$ & $\begin{array}{l}1335 \\
1351 \\
1353\end{array}$ & & Lettré & $\begin{array}{l}\text { Officer } \mathrm{du} \\
\text { roi }\end{array}$ \\
\hline $\begin{array}{ll}\text { Gonçalo } & \\
\text { Vasques } & \text { de } \\
\text { Azevedo } & \\
\end{array}$ & [1336-1338] & & Noble & \\
\hline Gil Martins & 1345 & & Clerc & $\begin{array}{l}\text { Chanoine de } \\
\text { Lisbonne }\end{array}$ \\
\hline $\begin{array}{l}\text { Maître João de } \\
\text { Lisboa (Mestre } \\
\text { João das Leis) }\end{array}$ & 1345 & & Lettré & $\begin{array}{l}\text { Conseiller } \\
\text { du roi }\end{array}$ \\
\hline $\begin{array}{l}\text { Fernando } \\
\text { Gonçalves } \\
\text { Cogominho }\end{array}$ & 1345 & & Noble & $\begin{array}{l}\text { Conseiller } \\
\text { du roi }\end{array}$ \\
\hline Gonçalo & 1347 & & $\begin{array}{l}\text { Noble } \\
\text { Chevalier }\end{array}$ & \\
\hline $\begin{array}{l}\text { Geraldo Esteves } \\
\text { de Santarém }\end{array}$ & 1350 & $\begin{array}{ll}\text { Curie } & (1361, \\
1363, & 1365- \\
1366) & \end{array}$ & & $\begin{array}{lr}\text { Surjuge } & \mathrm{du} \\
\text { roi; } & \text { auditeur } \\
\mathrm{du} & \text { roi } \\
\text { Alphonse IV }\end{array}$ \\
\hline $\begin{array}{l}\text { João Afonso, } \\
\text { professeur de } \\
\text { droit civil }\end{array}$ & 1352 & & Lettré & $\begin{array}{l}\text { Prieur de } \\
\text { Guimarães; } \\
\text { évêque } \\
\text { d'Évora }\end{array}$ \\
\hline $\begin{array}{l}\text { Gonçalo } \\
\text { Mendes de } \\
\text { Vasconcelos }\end{array}$ & 1352 & & Noble & \\
\hline Rodrigo Gomes & 1353 & & & \\
\hline $\begin{array}{l}\text { Afonso } \\
\text { Raimundo/ } \\
\text { Maître Afonso } \\
\text { das Leis }\end{array}$ & 1355 & Curie (1361) & $\begin{array}{l}\text { Lettré } \\
\text { Clerc } \\
\text { d'ordres } \\
\text { mineurs } \\
\end{array}$ & $\begin{array}{l}\text { Vedor de la } \\
\text { chancellerie } \\
\text { du roi }\end{array}$ \\
\hline Vasco Martins & 1356 & & Chevalier & \\
\hline Álvaro Soares & 1357 & & Chevalier & \\
\hline $\begin{array}{l}\text { João Lourenço } \\
\text { da Covilhã }\end{array}$ & 1357 & & Chevalier & \\
\hline
\end{tabular}


3)Règne de Pierre $\mathrm{I}^{\mathrm{er}}(1357-1367)$

\begin{tabular}{|l|l|l|l|l|}
\hline $\begin{array}{c}\text { Agents } \\
\text { diplomatiques }\end{array}$ & $\begin{array}{c}\text { Ambassades à } \\
\text { la Curie }\end{array}$ & $\begin{array}{c}\text { Autres } \\
\text { ambassades }\end{array}$ & Statut & $\begin{array}{c}\text { Charges, } \\
\text { offices, } \\
\text { dignités }\end{array}$ \\
\hline $\begin{array}{l}\text { Martim de } \\
\text { Vasques dóis }\end{array}$ & 1358 & & Noble & \\
\hline $\begin{array}{l}\text { Geraldo Esteves } \\
\text { [de Santarém] }\end{array}$ & 1361 & Curie (1350) & Noble & \\
\hline $\begin{array}{l}\text { maître Afonso } \\
\text { das Leis/Afonso } \\
\text { Raimundo }\end{array}$ & $1363-1366$ & Curie (1355) & $\begin{array}{l}\text { Lettré } \\
\text { Clerc } \\
\text { d'ordres } \\
\text { mineurs }\end{array}$ & \\
\hline $\begin{array}{l}\text { Vasco Martins } \\
\text { [Leitão] }\end{array}$ & & & $\begin{array}{l}\text { Noble } \\
\text { Chevalier }\end{array}$ & \\
\hline
\end{tabular}

4)Règne de Ferdinand $\mathrm{I}^{\mathrm{er}}$ (1367-1377)

\begin{tabular}{|l|l|l|l|l|}
\hline $\begin{array}{c}\text { Agents } \\
\text { diplomatiques }\end{array}$ & $\begin{array}{c}\text { Ambassades à } \\
\text { la Curie }\end{array}$ & $\begin{array}{c}\text { Autres } \\
\text { ambassades }\end{array}$ & Statut & $\begin{array}{c}\text { Charges, } \\
\text { offices, } \\
\text { dignités }\end{array}$ \\
\hline $\begin{array}{l}\text { Lourenço } \\
\text { Gonçalves }\end{array}$ & 1370 & & Chevalier & $\begin{array}{l}\text { Surjuge, } \\
\text { auditeur, } \\
\text { corregedor } \\
\text { du roi }\end{array}$ \\
\hline $\begin{array}{l}\text { Afonso } \\
\text { Domingues [de } \\
\text { Beja] }\end{array}$ & 1370 & & Chevalier & $\begin{array}{l}\text { Auditeur, } \\
\text { surjuge, } \\
\text { desembarga } \\
\text { dor et } \\
\text { conseiller du } \\
\text { roi }\end{array}$ \\
\hline Gonçalo Peres & 1372 & & Noble & \\
\hline
\end{tabular}




\begin{tabular}{|c|c|c|c|c|}
\hline Martinho Gil & 1374 & & Clerc & $\begin{array}{l}\text { Évêque } \\
\text { d'Évora }\end{array}$ \\
\hline $\begin{array}{l}\text { Vasco } \\
\text { Gonçalves }\end{array}$ & 1374 & & Clerc & $\begin{array}{l}\text { Chanoine de } \\
\text { Lisbonne }\end{array}$ \\
\hline Martinho & 1376 & & Clerc & $\begin{array}{l}\text { Évêque de } \\
\text { Silves }\end{array}$ \\
\hline Martinho & 1376 & & Clerc & $\begin{array}{l}\text { Abbé } \\
\text { d'Alcobaça }\end{array}$ \\
\hline $\begin{array}{l}\text { Alvaro } \\
\text { Gonçalves de } \\
\text { Moura }\end{array}$ & 1376 & & Noble & \\
\hline Pedro Cavaleiro & 1377 & & Clerc & $\begin{array}{l}\text { Archidiacre } \\
\text { de } \\
\text { Lisbonne; } \\
\text { évêque de } \\
\text { Silves }\end{array}$ \\
\hline $\begin{array}{l}\text { Lourenço Eanes } \\
\text { Fogaça }\end{array}$ & 1377 & $\begin{array}{l}\text { Castille (1374) } \\
\text { France (1378) } \\
\text { Angleterre } \\
(1380)\end{array}$ & $\begin{array}{l}\text { Clerc puis } \\
\text { chevalier }\end{array}$ & $\begin{array}{l}\text { Chancelier } \\
\text { de Ferdinand } \\
\text { I }^{\text {er }}\end{array}$ \\
\hline
\end{tabular}

